Article

\title{
Discovery of Novel c-Met Inhibitors Bearing a 3-Carboxyl Piperidin-2-one Scaffold
}

\author{
Wei Zhang ${ }^{1}$, Jing Ai ${ }^{2}$, Dakuo Shi ${ }^{3}$, Xia Peng ${ }^{2}$, Yinchun $\mathrm{Ji}^{2}$, Jian Liu ${ }^{1}$, Meiyu Geng ${ }^{2, *}$ and \\ Yingxia Li ${ }^{1, *}$ \\ 1 School of Pharmacy, Fudan University, Shanghai 201203, China \\ 2 Division of Antitumor Pharmacology, State Key Laboratory of Drug Research, Shanghai Institute \\ of Materia Medica, Chinese Academy of Sciences, Shanghai 201203, China \\ 3 School of Pharmacy, Ocean University of China, Qingdao 266003, China \\ * Authors to whom correspondence should be addressed; E-Mails: mygeng@simm.ac.cn (M.G.); \\ liyx417@fudan.edu.cn (Y.L.); Tel./Fax: +86-21-5198-0127 (Y.L.).
}

Received: 21 January 2014; in revised form: 13 February 2014 / Accepted: 14 February 2014 / Published: 24 February 2014

\begin{abstract}
A series of compounds containing a novel 3-carboxypiperidin-2-one scaffold based on the lead structure BMS-777607 were designed, synthesized and evaluated for their c-Met kinase inhibition and cytotoxicity against MKN45 cancer cell lines. The results indicated that five compounds exhibited significant inhibitory effect on c-Met with $\mathrm{IC}_{50}$ values of $8.6-81 \mathrm{nM}$ and four compounds showed potent inhibitory activity against MKN45 cell proliferation, with $\mathrm{IC}_{50}$ s ranging from $0.57-16 \mu \mathrm{M}$.
\end{abstract}

Keywords: c-Met; synthesis; kinase inhibitor; 3-carboxypiperidin-2-one

\section{Introduction}

c-Met kinase is a transmembrane receptor tyrosine kinase (RTK). Upon binding of its endogenous ligand hepatocyte growth factor (HGF, also known as scatter factor, SF), c-Met receptor undergoes dimerization and in turn triggers signal transducers to mediate a variety of cellular responses such as cell growth, invasion, migration and survival [1,2]. The normal c-Met/HGF pathway plays an important role in embryogenesis and wound healing, but aberrant forms of this pathway (for example, as a result of overexpression of c-Met and HGF) have frequently been observed in a variety of human solid tumors and hematologic malignancies. Importantly, both increased levels of c-Met and HGF have 
been associated with poor clinical outcomes [3-5]. Therefore, c-Met has been pursued as an attractive anticancer drug target for the past two decades [6,7]. Several approaches to inhibition of the HGF/c-Met pathway in cancer cells have been reported, such as antagonistic ligands to c-Met, antibodies against HGF or c-Met, and small molecule c-Met inhibitors [8-10].

During the development of small molecular c-Met kinase inhibitors, a compound disclosed by Kirin Brewery Company in 2003 [11] could be regarded as a milestone (Figure 1). Structurally, this compound (1) is composed of four moieties: a phenyl group (moiety A), a bridge moiety B, an ortho-fluoro phenol and a 6,7-dimethoxyquinoline. Initiated by this discovery, numerous c-Met kinase inhibitors bearing diverse chemical scaffolds have been reported. Generally, structural optimization based on compound 1 mainly focused on moiety D and B. Replacement of the 6,7-dimethoxyquinoline moiety by various $N$-containing heterocycles, such as substituted quinoline [12], thienopyridine [13-15], pyrrolopyridine [16], aminopyridine [17], thienopyrimidine [18], furopyrimidine [18], imidazopyridine [19] or imidazopyridazine [19], has been investigated. The bridge moiety B connecting moiety $\mathrm{A}$ and $\mathrm{C}$ was designed as linear [20-22] or cyclic [14,15,23-26], bearing at least one amide bond with 5-atoms in the main chain [22,24] (i.e., six chemical bonds distance between moiety A and C, Figure 1). However, there are little changes to moiety A and C, except for phenyl ring or substituted phenyl ring modifications to the former.

Figure 1. Representative scaffolds used for the structural optimization of c-Met inhibitors.

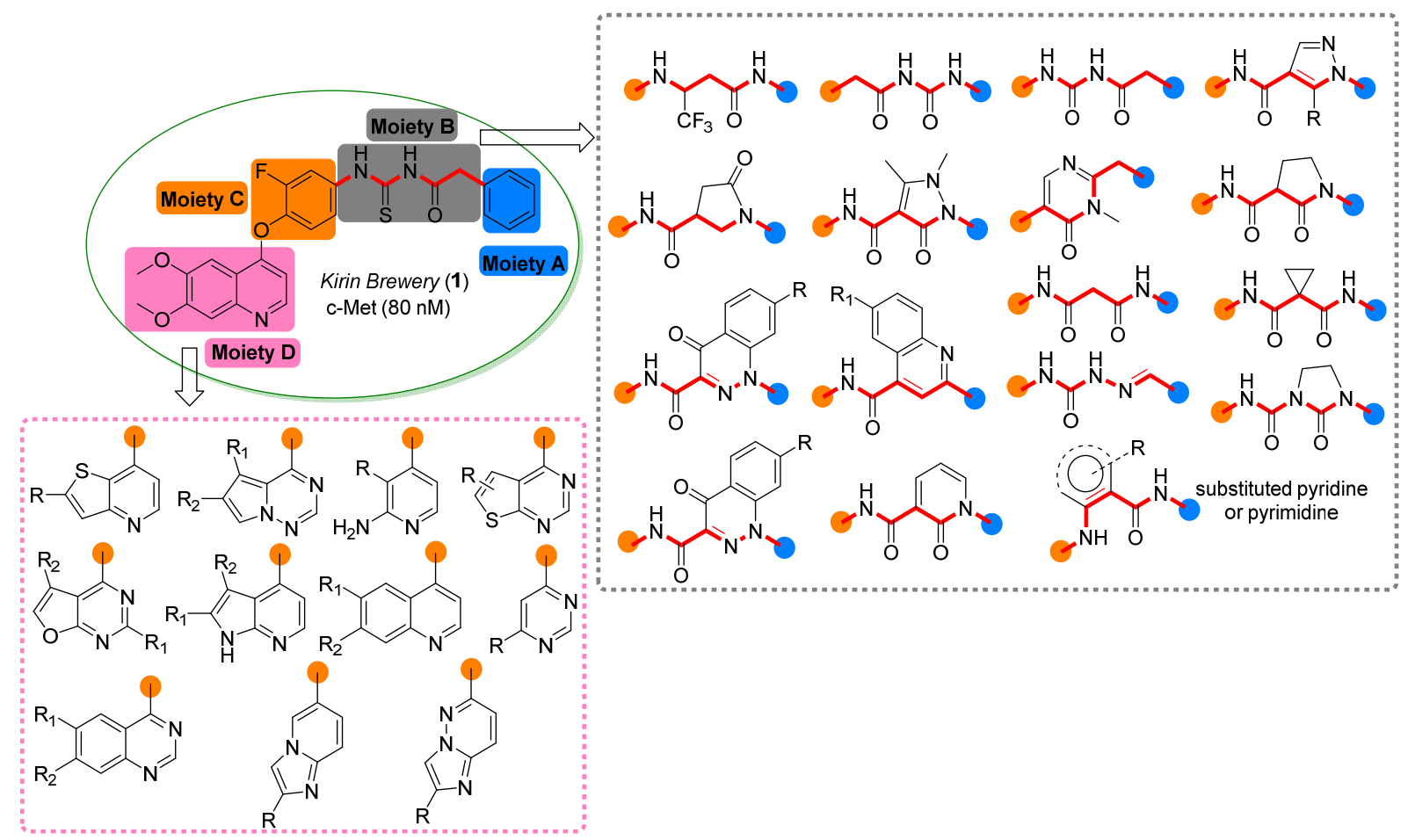

A good example for these inhibitors is BMS-777067, which is now in phase 2 trial because of its excellent in vivo efficacy and favorable pharmacokinetic and preclinical safety profiles [17]. Taking BMS-777607 as leading compound, the design and synthesis of new derivatives with novel structures are under study in our laboratory. Preliminary investigation indicated that 3-carboxypiperidin-2-one is a promising scaffold for the design of new c-Met inhibitors. Herein we would like to report our efforts in this respect (Figure 2). 
Figure 2. Scaffolds used for the structural optimization based on BMS-777607 in this paper.

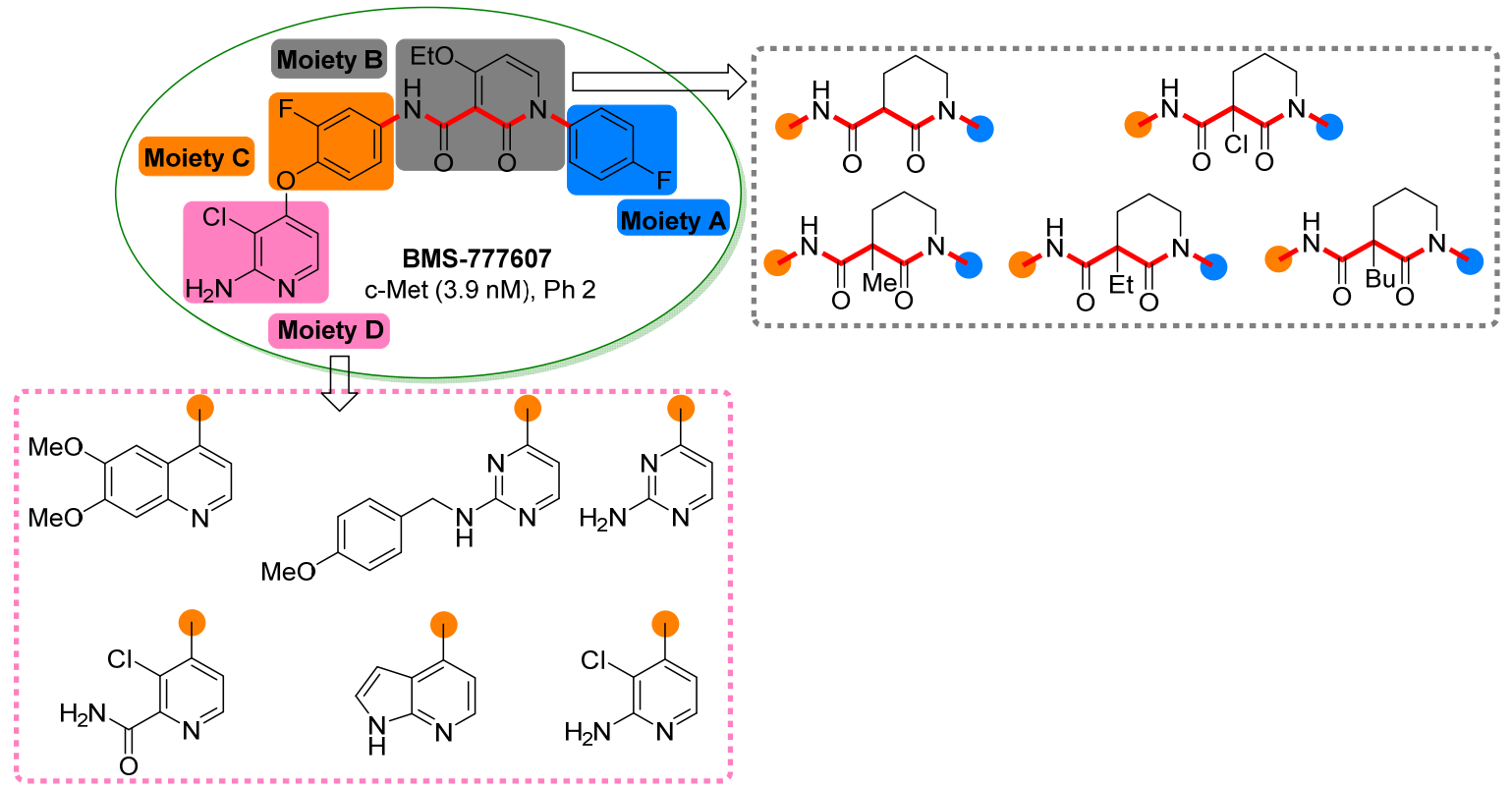

\section{Results and Discussion}

\subsection{Chemistry}

As shown in Scheme 1, saponification of isobutyl ester 2 with lithium hydroxide gave the piperidinone 3 -carboxylic acid 3, which could be further brominated giving compound 4 in $92 \%$ yield. On the other hand, deprotonation of compound $\mathbf{2}$ with sodium hydride, followed by treatment with an alkyl halide (MeI, EtBr, or $n$-BuBr) led to the corresponding $\alpha$-substituted piperidinones. Saponification of these esters 5a-c gave the corresponding carboxylic acids smoothly. In this way, we had five carboxylic acids (compounds $\mathbf{3}, \mathbf{4}, \mathbf{6 a}-\mathbf{c}$ ) in hand, which would be used in next coupling step.

Scheme 1. Synthesis of the piperidinone 3-carboxylic acids 3, 4 and $\mathbf{6 a}-\mathbf{c}$.

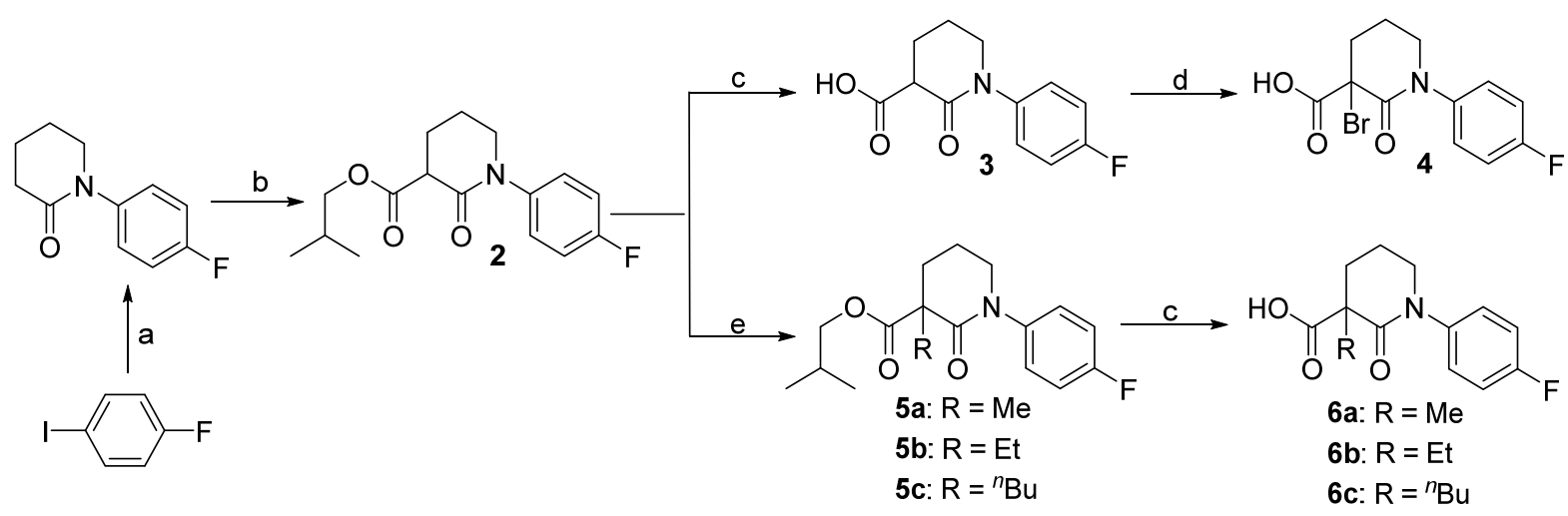

Reagents and conditions: (a) piperidin-2-one, $\mathrm{CuI}, \mathrm{K}_{3} \mathrm{PO}_{4}, \mathrm{DMF}, 90 \%$; (b) t-BuLi, isobutyl chloroformate, $82 \%$; (c) $\mathrm{LiOH}, \mathrm{THF} / \mathrm{MeOH} / \mathrm{H}_{2} \mathrm{O}, 87 \%$ for 3, $88 \%$ for $\mathbf{6 a}, 79 \%$ for $\mathbf{6 b}, 84 \%$ for $\mathbf{6 c}$; (d) $\mathrm{Br}_{2} / \mathrm{Et}_{2} \mathrm{O}, 92 \%$; (e) $\mathrm{NaH} / \mathrm{MeI}, 87 \%$ for $\mathbf{5 a}$; $\mathrm{NaH} / \mathrm{EtBr}, 76 \%$ for $\mathbf{5 b}$; $\mathrm{NaH} / n-\mathrm{BuBr}, 83 \%$ for $\mathbf{5 c}$.

Deprotonation of 3,4-dichloropyridine (7) with lithium 2,2,6,6-tetramethylpiperidide (TMPLi) followed by treated with trimethylsilyl isothiocyanate and acidic workup, gave 3,4-dichloropicolinamide 
(8) in $40 \%$ yield (Scheme 2). This pyridyl chloride was coupled with 4-amino-2-fluorophenol in the presence of potassium tert-butoxide to afford the aromatic amine 9 in $72 \%$ yield. Similarly, coupling of phenol (10) with 4-chloro-7H-pyrrolo[2,3-d]pyrimidine and 4-chloro-6,7-dimethoxyquinoline followed by conversion of the nitryl to an amino group gave amines 11 and 14, respectively. For the preparation of substituted pyrimidine 13, the amino group was introduced to the C-2 position before zinc-mediated reduction. Thus we had four aromatic amines (compounds 9, 11, 13 and 14) in hand, which were subjected to the next step directly.

Scheme 2. Synthesis of aromatic amines 9, 11, 13 and 14.<smiles>Cc1cc(Cl)c(Cl)c(C(N)=O)n1</smiles><smiles>COc1ccc(CNc2nccc(Oc3ccc(N)cc3F)n2)cc1CNc1ccc(Cl)c2cc(OC)c(OC)cc12</smiles>

Reagents and conditions: (a) TMPLi, trimethylsilyl isothiocyanate, $-78{ }^{\circ} \mathrm{C}, 40 \%$; (b) $t$-BuOK, 4-amino-2fluorophenol, 72\%; (c) $\mathrm{PhBr}, 130{ }^{\circ} \mathrm{C}$, 85\%; (d) $\mathrm{Zn}, \mathrm{NH}_{4} \mathrm{Cl}, 88 \%$ for 11, 69\% for 13; 91\% for 14; (e) $\mathrm{K}_{2} \mathrm{CO}_{3}$, DMF; (f) 4-methoxybenzylamine, $\mathrm{K}_{2} \mathrm{CO}_{3}, 68 \%$.

Coupling of aromatic amines 9, 11, 13 or 14 with the 3-carboxypiperidin-2-one 3 in the presence of 1-ethyl-3-(3-dimethylaminopropyl)-carbodiimide hydrochloride (EDC-HCl) and N,N-dimethyl-4amino pyridine (DMAP) gave the corresponding amides 15a, 17a, 18a or 20a, respectively (Scheme 3). When bromide 4 was used as the carboxylic acid component, halo-exchanged products $\mathbf{1 5 b}, \mathbf{1 7 b}, \mathbf{1 8 b}$, 20b were observed (confirmed by NMR and MS). The aminopyridine-containing products $\mathbf{1 6} \mathbf{a}-\mathbf{b}$ were achieved after Hoffman degradation and the aminopyrimidine derivates 19a-b were generated after treatment of $\mathbf{1 8 a}-\mathbf{b}$ with trifluoroacetic acid (TFA). 
Scheme 3. Synthesis of the newly designed c-Met inhibitors 15-20.

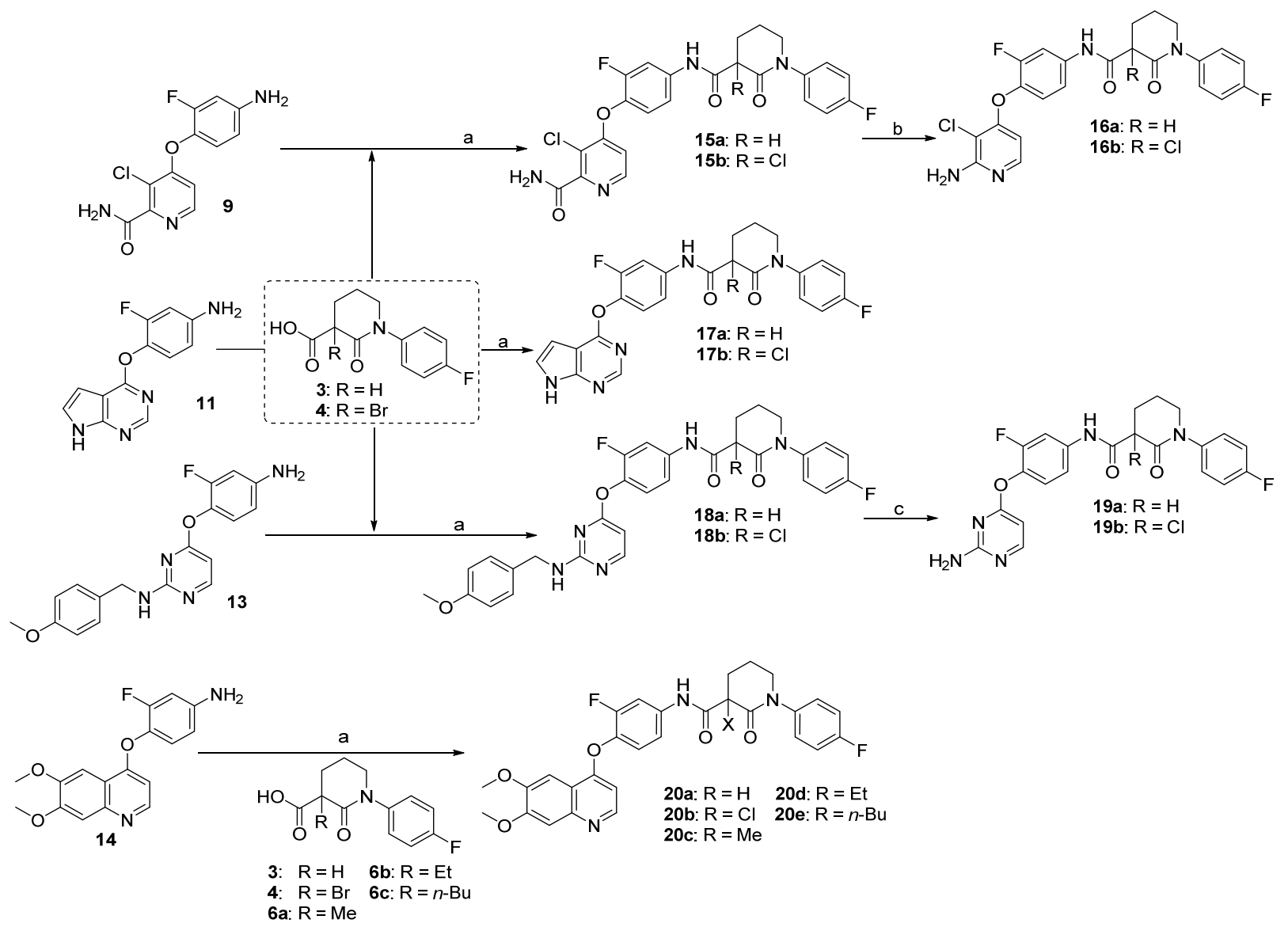

Reagents and conditions: (a) EDC-HCl, DMAP, $76 \%$ for $\mathbf{1 5 a}, 68 \%$ for $\mathbf{1 5 b}, 31 \%$ for $\mathbf{1 7 a}, 42 \%$ for $\mathbf{1 7 b}, 69 \%$ for $\mathbf{1 8 a}, 57 \%$ for $\mathbf{1 8 b}, 61 \%$ for $\mathbf{2 0 a}, 54 \%$ for $\mathbf{2 0 b}, 68 \%$ for $\mathbf{2 0 c}, 58 \%$ for $\mathbf{2 0 d}, 64 \%$ for $\mathbf{2 0 e}$; (b) $\mathrm{PhI}(\mathrm{OAc})_{2}$, $72 \%$ for $16 a, 76 \%$ for $16 b ;$; (c) TFA, $71 \%$ for $19 a, 58 \%$ for $19 b$.

\subsection{Evaluation of Biological Activity}

As illustrated in Table 1, all of the compounds bearing a 3-carboxypiperidin-2-one scaffold exhibit potent c-Met kinase inhibition activity. However, compounds lacking an $\alpha$-substituent group (15a, 17a, 18a, 19a, 20a) only showed much less potent anti-c-Met kinase activity. When the $\alpha$-proton was substituted by chlorine, the activity generally increased ( $c f$. 15b vs. 15a, 16b $v s .16 \mathbf{a}, 20 \mathbf{b} v s .20 \mathbf{a}$ ). When alkyl groups (Me, Et, or $n-\mathrm{Bu}$ ) were introduced to this position, the inhibitory effects were greatly enhanced (20c, 20d and 20e vs. 20a). Among these three derivatives, the smallest methyl group was the most favorable among the compounds exerting inhibitory activity against c-Met kinase activity and c-Met-driven cell proliferation. Generally, 6,7-dimethoxyquinoline -containing analogues showed more potency than the pyrropyridine, pyrimidine, or aminopyrimidine counterparts (20b vs. 15b, 16b, 17b, 18b, 19b) according to the biological activity results. The most potent analogue 20b exhibited significant potency against c-Met kinase and c-Met-driven MKN45 cell proliferation, with $\mathrm{IC}_{50}$ values of $8.6 \mathrm{nM}$ and $0.57 \mu \mathrm{M}$, respectively. Other three analogues $\mathbf{2 0 c}-\mathbf{e}$ with alkyl substitution in the piperidone moiety are also promising, showing inhibitory activity against c-Met enzymatic activities with the $\mathrm{IC}_{50} \mathrm{~S}$ of $11.2 \sim 64.0 \mathrm{nM}$ and inhibiting MKN45 cell proliferation with $\mathrm{IC}_{50} \mathrm{~S}$ of $0.65 \sim 16.0 \mu \mathrm{M}$, individually. 
Table 1. SAR of the compounds bearing a 3-carboxypiperidin-2-one scaffold.

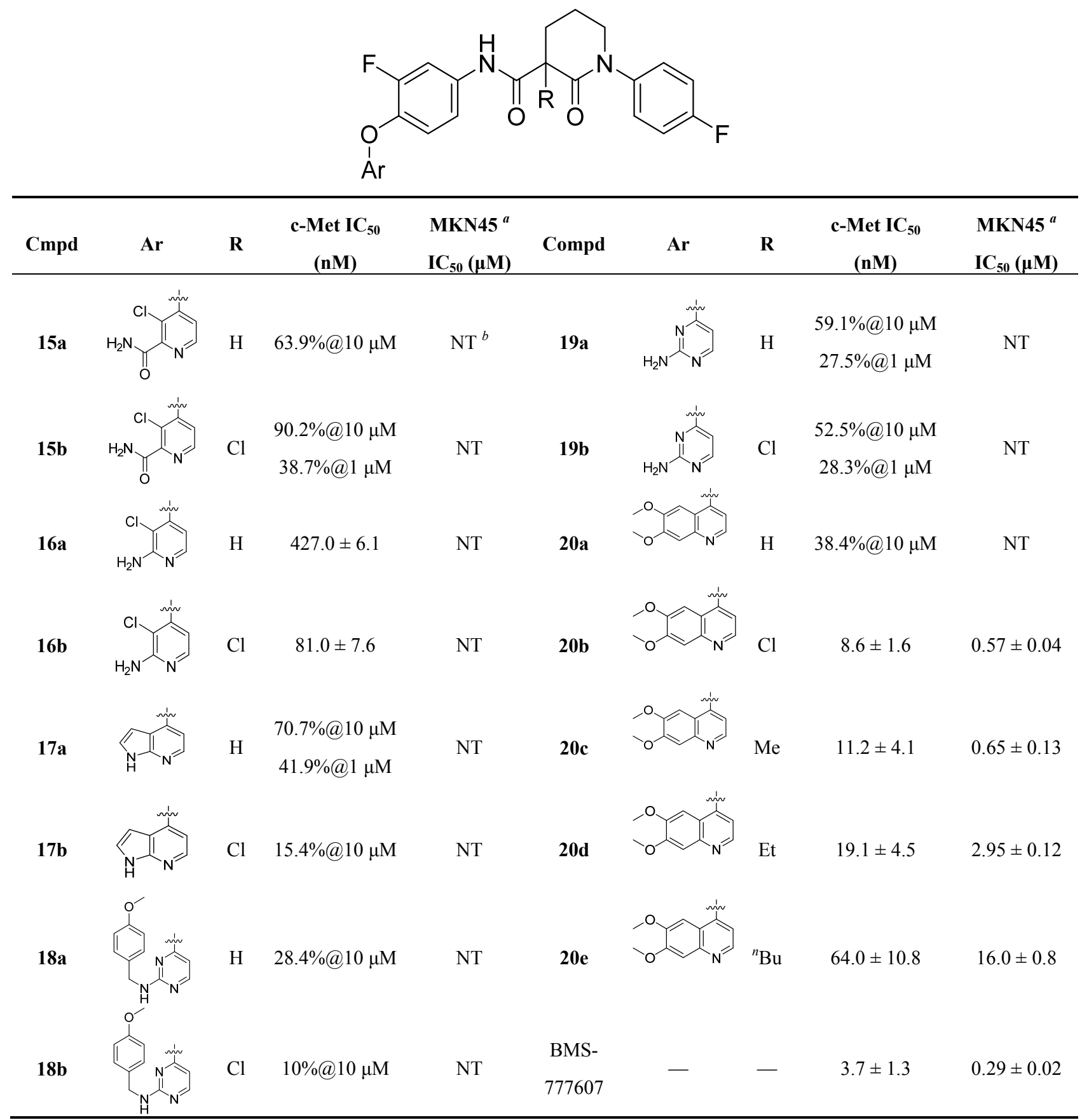

${ }^{a}$ : MKN45, human gastric cancer cell line that expresses elevated levels of constitutively active c-Met; ${ }^{b}: \mathrm{NT}$, Not tested.

\subsection{Molecular Modeling}

To further elucidate the binding mode of compounds, docking analysis was performed. In our study, the co-crystal structure of BMS-777607 with c-Met kinase (PDB ID:3F82) was selected as the docking model. The inhibitor was docked using the GLIDE docking algorithm [27] in the XP (extra precision) mode. A binding model for $(R)-20 b$ in the ATP binding site is presented in Figure 3a. The resulting model successfully identifies key hydrogen bond interaction and hydrophobic interactions between the ligands and residues of the protein's ATP binding pocket. The carbonyl oxygen of the 
3-carboxypiperidin-2-one and the nitrogen atom of the quinoline ring in $\mathbf{2 0 b}$ formed hydrogen bonding interactions with Asp1222 and Met1160, respectively. $\pi-\pi$ Interactions were formed between the phenyl ring (moiety $\mathrm{C}$ ) and Phe1223. In addition, hydrophobic interactions were formed between the phenyl ring (moiety A) in 20b and Phe1134, Phe1200. A binding model for $(S)$-20b in the ATP binding site is presented in Figure $3 \mathrm{~b}$. However, this compound failed to dock into the binding pocket, as the orientation of the ligand in the binding model was opposite to that of BMS-777607. Therefore, we postulate that the requisite chirality for these compound may be the $R$-configuration. We are now seeking an efficient route to access the enantiomers, and the optical pure compounds will be synthesized and evaluated in the due course.

Figure 3. Binding poses of compounds $(R)-\mathbf{2 0 b}$ and $(S)-20 b$ with c-Met.

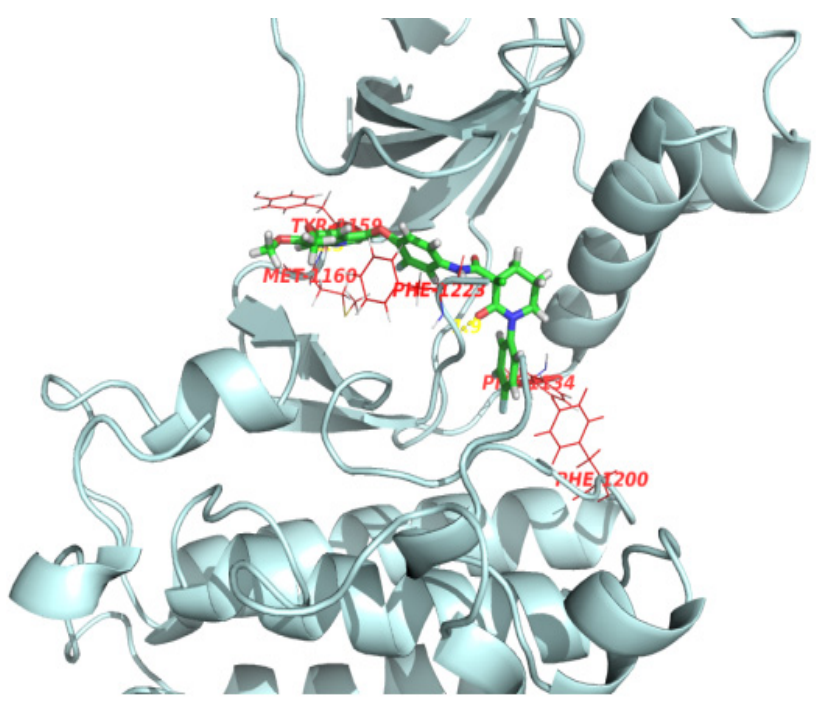

(a)

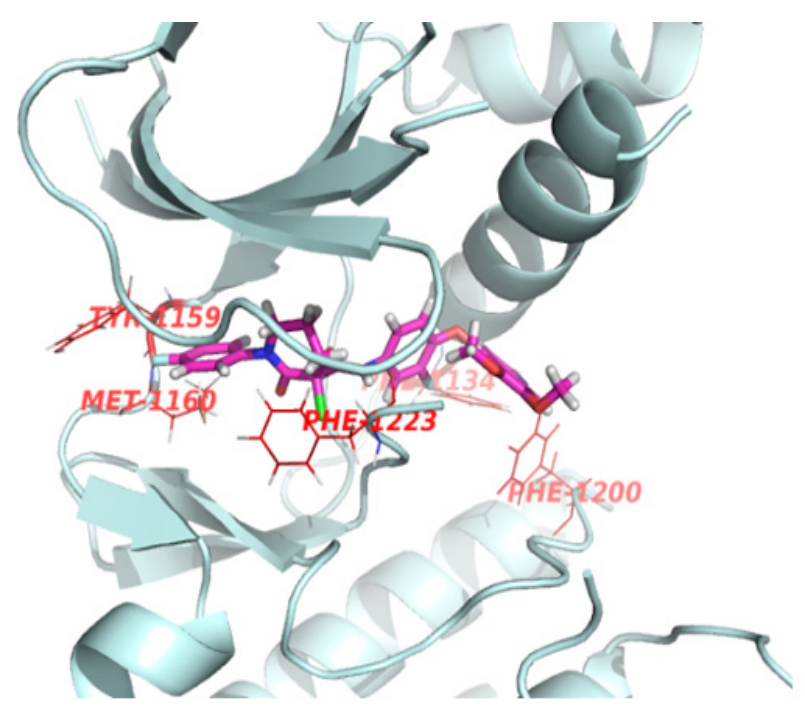

(b)

\section{Experimental}

\subsection{General Information}

All chemical reagents were used as supplied unless indicated. Solvents used in organic reactions were distilled under an inert atmosphere. Unless otherwise noted, all reactions were carried out at room temperature and performed under a positive pressure of argon. Flash column chromatography was performed on silica gel (200-300 mesh, Qingdao Haiyang Chemical Co., Ltd, Qingdao, China). Analytical thin layer chromatography (TLC) was performed on glass plates pre-coated with a $0.25 \mathrm{~mm}$ thickness of silica gel. ${ }^{1} \mathrm{H}-\mathrm{NMR}$ and ${ }^{13} \mathrm{C}-\mathrm{NMR}$ spectra were taken on a Jeol JNM-ECP 600 spectrometer (Jeol Ltd., Tokyo, Japan) at room temperature. Chemical shifts of the ${ }^{1} \mathrm{H}-\mathrm{NMR}$ spectra are expressed in ppm relative to the solvent residual signal 7.26 in $\mathrm{CDCl}_{3}$ or to tetramethylsilane $(\delta=0.00)$. Chemical shifts of the ${ }^{13} \mathrm{C}$-NMR spectra are expressed in ppm relative to the solvent signal 77.00 in $\mathrm{CDCl}_{3}$ or to tetramethylsilane $(\delta=0.00)$ unless otherwise noted. Electrospray (ESI) mass spectra were recorded on a Global Q-TOF mass spectrometer (Waters, Wilford, MA, USA). 


\subsection{Synthesis}

Isobutyl 1-(4-fluorophenyl)-2-oxopiperidine-3-carboxylate (2). 1-Fluoro-4-iodobenzene (2.22 g, $10 \mathrm{mmol}$ ) and piperidin-2-one (1.2 g, $12 \mathrm{mmol})$ were added to dry DMF $(30 \mathrm{~mL})$, followed by the addition of $\mathrm{K}_{3} \mathrm{PO}_{4}(6.36 \mathrm{~g}, 30 \mathrm{mmol})$ and $\mathrm{CuI}(190 \mathrm{mg}, 0.1 \mathrm{mmol})$. The mixture was heated to $100{ }^{\circ} \mathrm{C}$ for $12 \mathrm{~h}$ before filtering through Celite. After washing with ethyl acetate $(3 \times 10 \mathrm{~mL})$, the combined organic phase was concentrated and the residue was purified by column chromatography to give 1-(4fluorophenyl)piperidin-2-one $(1.73 \mathrm{~g}, 90 \%)$ as a yellow solid. This $\mathrm{N}$-arylpiperidin-2-one (386 $\mathrm{mg}$, $2 \mathrm{mmol})$ was dissolved in dry THF $(20 \mathrm{~mL})$ and cooled to $-78^{\circ} \mathrm{C}$. After the addition of tert-BuLi $(1.4 \mathrm{~mL}$, 1.6 $\mathrm{M}$ in THF, $2.2 \mathrm{mmol}$ ) and stirring at this temperature for $4 \mathrm{~h}$, isobutyl chlorofomate $(400 \mu \mathrm{L}, 2 \mathrm{mmol})$ was added. Ten min later, the reaction was quenched by addition of saturated aq. $\mathrm{NH}_{4} \mathrm{Cl}(2 \mathrm{~mL})$. The mixture was diluted with water $(20 \mathrm{~mL})$ and extracted with EtOAc $(3 \times 20 \mathrm{~mL})$. The combined organic layer was washed with brine, dried over $\mathrm{Na}_{2} \mathrm{SO}_{4}$, and concentrated in vacuo. The residue was purified by column chromatography to give compound $2(480 \mathrm{mg}, 82 \%)$ as a yellow wax. ${ }^{1} \mathrm{H}-\mathrm{NMR}(600 \mathrm{MHz}$, $\left.\mathrm{CDCl}_{3}\right) \delta 7.25-7.20(\mathrm{~m}, 2 \mathrm{H}, \mathrm{ArH}), 7.09-7.03(\mathrm{~m}, 2 \mathrm{H}, \mathrm{ArH}), 3.99(\mathrm{dd}, 1 \mathrm{H}, J=10.6,6.7 \mathrm{~Hz}, \mathrm{CH}), 3.83$ (d, $1 \mathrm{H}, J=6.7 \mathrm{~Hz}, \mathrm{CHH}), 3.70-3.61(\mathrm{~m}, 1 \mathrm{H}, \mathrm{CHH}), 3.58$ (t, $1 \mathrm{H}, J=6.9 \mathrm{~Hz}, \mathrm{CH}), 2.32-2.24(\mathrm{~m}, 1 \mathrm{H}$, $\mathrm{CHH}), 2.23-2.16(\mathrm{~m}, 1 \mathrm{H}, \mathrm{CHH}), 2.12-2.04(\mathrm{~m}, 1 \mathrm{H}, \mathrm{CHH}), 2.02-1.87(\mathrm{~m}, 2 \mathrm{H}, \mathrm{CH}, \mathrm{CHH}), 0.94(\mathrm{~d}, 6 \mathrm{H}$, $\left.J=6.6 \mathrm{~Hz}, \mathrm{CH}_{3}\right) ;{ }^{13} \mathrm{C}-\mathrm{NMR}\left(150 \mathrm{MHz}, \mathrm{CDCl}_{3}\right) \delta 171.0,166.3,162.1,160.4,138.8,127.9,116.2$, 100.0, 71.5, 51.6, 49.6, 27.8, 25.3, 21.4, 19.1; HR-MS (ESI) Calcd for $\mathrm{C}_{16} \mathrm{H}_{21} \mathrm{FNO}_{3}[\mathrm{M}+\mathrm{H}]^{+}$ 294.1506, Found 294.1518.

1-(4-Fluorophenyl)-2-oxopiperidine-3-carboxylic acid (3). To a solution of 2 (217 $\mathrm{mg}, 0.74 \mathrm{mmol})$ in $\mathrm{THF} / \mathrm{MeOH} / \mathrm{H}_{2} \mathrm{O}\left(1 / 1 / 1,3 \mathrm{~mL}\right.$ in total) at $0{ }^{\circ} \mathrm{C}$ was added $\mathrm{LiOH}$ monohydrate $(94 \mathrm{mg}, 2.2 \mathrm{mmol})$. The reaction mixture was warmed to room temperature and stirred for $5 \mathrm{~h}$. The solution was acidified to $\mathrm{pH}$ 1 with $1 \mathrm{~mol} / \mathrm{L} \mathrm{HCl}$ and extracted with EtOAc $(3 \times 20 \mathrm{~mL})$. The organic extracts were combined and washed with brine $(2 \times 5 \mathrm{~mL})$. Evaporation of the solvent gave the corresponding acid 3 (152 mg, $87 \%)$ as a white solid. ${ }^{1} \mathrm{H}-\mathrm{NMR}\left(600 \mathrm{MHz}, \mathrm{CDCl}_{3}\right) \delta 7.33-7.28(\mathrm{~m}, 1 \mathrm{H}, \mathrm{ArH}), 7.25-7.19(\mathrm{~m}, 1 \mathrm{H}$, ArH), 3.69-3.55 (m, 2H, NCH2), 3.43 (dd, 1H, J=8.2, 6.5 Hz, CH), 2.16-2.10 (m, 1 H, CHH), 2.08-2.02 $(\mathrm{m}, 1 \mathrm{H}, \mathrm{CHH}), 1.98-1.91(\mathrm{~m}, 1 \mathrm{H}, \mathrm{CHH}), 1.91-1.83(\mathrm{~m}, 1 \mathrm{H}, \mathrm{CHH}) ;{ }^{13} \mathrm{C}-\mathrm{NMR}\left(150 \mathrm{MHz}, \mathrm{CDCl}_{3}\right) \delta$ 174.3, 170.2, 161.3, 159.6, 138.7, 127.9, 115.6, 51.8, 50.3, 27.5, 21.6; HR-MS (ESI) Calcd for $\mathrm{C}_{12} \mathrm{H}_{13} \mathrm{FNO}_{3} 238.0880[\mathrm{M}+\mathrm{H}]^{+}$, found 238.0910.

3-Bromo-1-(4-fluorophenyl)-2-oxopiperidine-3-carboxylic acid (4). To a solution of acid 3 (220 mg, $0.93 \mathrm{mmol})$ in $\mathrm{Et}_{2} \mathrm{O}(5 \mathrm{~mL})$ was added liquid $\mathrm{Br}_{2}(48 \mu \mathrm{L}, 0.93 \mathrm{mmol})$ at $0{ }^{\circ} \mathrm{C}$. The reaction mixture was stirred for $2 \mathrm{~h}$ before concentrated in vacuo. The residue was purified by column chromatography, giving compound $4(265 \mathrm{mg}, 91 \%)$ as white solid. ${ }^{1} \mathrm{H}-\mathrm{NMR}\left(600 \mathrm{MHz}\right.$, acetone- $\left.d_{6}\right) \delta 13.03(\mathrm{~s}, 1 \mathrm{H}$, $\mathrm{OH}), 7.44-7.40$ (m, 2H, ArH), 7.25-7.20 (m, 2H, ArH), 4.04 (td, 1H, J=12.1, 4.6 Hz, NCHH), 3.82 (ddt, $1 \mathrm{H}, J=13.0,6.3,2.4 \mathrm{~Hz}, \mathrm{NCHH}), 2.77-2.69$ (m, 1H, CHH), 2.62-2.56 (m, 1H, CHH), 2.53-2.43 $(\mathrm{m}, 1 \mathrm{H}, \mathrm{CHH}), 2.19-2.12(\mathrm{~m}, 1 \mathrm{H}, \mathrm{CHH}) ;{ }^{13} \mathrm{C}-\mathrm{NMR}\left(150 \mathrm{MHz}\right.$, acetone- $\left.d_{6}\right) \delta 166.4,162.5,160.9$, $140.6,140.6,129.0,129.0,116.2,52.1,32.3,20.4$. 
3.2.1. General Procedure for the Synthesis of Isobutyl 1-(4-Fluorophenyl)-3-alkyl-2-oxopiperidine-3carboxylates 5a-c

To a solution of compound $2(586 \mathrm{mg}, 2 \mathrm{mmol})$ in dry THF $(10 \mathrm{~mL})$ at $0{ }^{\circ} \mathrm{C}$ was added $\mathrm{NaH}(72 \mathrm{mg}$, $80 \%$ suspension in mineral oil, $2.4 \mathrm{mmol}$ ) in portions. Thirty min later, alkyl halide (MeI, EtBr, or $n$-BuBr, $2.6 \mathrm{mmol}$ ) was added slowly and the reaction mixture was stirred at this temperature for another $5 \mathrm{~h}$. When TLC showed all the starting material consumed, the reaction mixture was quenched with $0.5 \mathrm{~mol} / \mathrm{L} \mathrm{HCl}$, diluted with water $(20 \mathrm{~mL})$ and extracted with EtOAc $(3 \times 20 \mathrm{~mL})$. The combined organic layer was washed with brine, dried over $\mathrm{Na}_{2} \mathrm{SO}_{4}$ and concentrated. The residue was purified by column chromatography to give the desired compound as pale yellow oil.

Isobutyl 1-(4-fluorophenyl)-3-methyl-2-oxopiperidine-3-carboxylate (5a). 87\% yield; ${ }^{1} \mathrm{H}-\mathrm{NMR}(600 \mathrm{MHz}$, $\left.\mathrm{CDCl}_{3}\right) \delta 7.25-7.19(\mathrm{~m}, 1 \mathrm{H}, \mathrm{ArH}), 7.12-7.01(\mathrm{~m}, 1 \mathrm{H}, \mathrm{ArH}), 4.06-3.88\left(\mathrm{~m}, 2 \mathrm{H}, \mathrm{OCH}_{2}\right), 3.78-3.58(\mathrm{~m}$, $1 \mathrm{H}, \mathrm{CH} H), 2.47-2.31(\mathrm{~m}, 1 \mathrm{H}, \mathrm{CH} H), 2.10-1.94\left(\mathrm{~m}, 3 \mathrm{H}, \mathrm{CH}_{2}, \mathrm{CH}\right), 1.94-1.84(\mathrm{~m}, 1 \mathrm{H}, \mathrm{CH} H), 1.57$ (d, $\left.3 \mathrm{H}, J=2.4 \mathrm{~Hz}, \mathrm{CH}_{3}\right), 0.97\left(\mathrm{~d}, 3 \mathrm{H}, J=2.0 \mathrm{HzCH}_{3}\right), 0.96\left(\mathrm{~d}, 3 \mathrm{H}, J=2.1 \mathrm{~Hz}, \mathrm{CH}_{3}\right) ;{ }^{13} \mathrm{C}-\mathrm{NMR}(150 \mathrm{MHz}$, $\left.\mathrm{CDCl}_{3}\right) \delta 173.8,170.1,161.9,160.2,139.3,127.8,116.0,115.9,71.5,51.9,51.3,33.6,27.8,22.9$, 20.4, 19.2; HR-MS (ESI) Calcd for $\mathrm{C}_{17} \mathrm{H}_{23} \mathrm{FNO}_{3} 308.1662[\mathrm{M}+\mathrm{H}]^{+}$, found 308.1599.

Isobutyl 3-ethyl-1-(4-fluorophenyl)-2-oxopiperidine-3-carboxylate (5b). 76\% yield; ${ }^{1} \mathrm{H}-\mathrm{NMR}(600 \mathrm{MHz}$, $\left.\mathrm{CDCl}_{3}\right) \delta$ 7.24-7.18 (m, 2H, ArH), 7.08-7.03 (m, 2H, ArH), 4.01-3.90 (m, 2H, OCH$), 3.72-3.65$ (m, $1 \mathrm{H}, \mathrm{CHH}), 3.63-3.56(\mathrm{~m}, 1 \mathrm{H}, \mathrm{CHH}), 2.31-2.24(\mathrm{~m}, 1 \mathrm{H}, \mathrm{CHH}), 2.16-2.09$ (m, 1H, CHH), 2.10-2.04 (m, 1H, CHH), 2.02-1.91 (m, 4H, CH $), 0.98\left(\mathrm{t}, 3 \mathrm{H}, J=7.4 \mathrm{~Hz}, \mathrm{CH}_{3}\right), 0.96\left(\mathrm{~d}, 6 \mathrm{H}, J=2.1 \mathrm{~Hz}, 2 \times \mathrm{CH}_{3}\right.$ ); ${ }^{13} \mathrm{C}-\mathrm{NMR}\left(150 \mathrm{MHz}, \mathrm{CDCl}_{3}\right) \delta 173.6,170.0,161.8,160.2,139.3,127.8,116.0,71.5,51.9,51.3,33.6$, 30.1, 27.8, 22.9, 20.4, 19.8; HR-MS (ESI) Calcd for $\mathrm{C}_{18} \mathrm{H}_{25} \mathrm{FNO}_{3} 322.1819$ [M + H] $]^{+}$, found 322.1830.

Isobutyl 3-butyl-1-(4-fluorophenyl)-2-oxopiperidine-3-carboxylate (5c). 83\% yield; ${ }^{1} \mathrm{H}-\mathrm{NMR}(600 \mathrm{MHz}$, $\left.\mathrm{CDCl}_{3}\right) \delta 7.23-7.18(\mathrm{~m}, 2 \mathrm{H}, \mathrm{ArH}), 7.08-7.02(\mathrm{~m}, 2 \mathrm{H}, \mathrm{ArH}), 4.00-3.89$ (m, 2H, $\left.\mathrm{OCH}_{2}\right), 3.72-3.66$ (m, $1 \mathrm{H}, \mathrm{CHH}), 3.61-3.56(\mathrm{~m}, 1 \mathrm{H}, \mathrm{CHH}), 2.32-2.26(\mathrm{~m}, 1 \mathrm{H}, \mathrm{CHH}), 2.10-1.86(\mathrm{~m}, 6 \mathrm{H}), 1.46-1.38(\mathrm{~m}, 1 \mathrm{H}$, $\mathrm{CHH}), 1.37-1.29\left(\mathrm{~m}, 2 \mathrm{H}, \mathrm{CH}_{2}\right), 1.30-1.21(\mathrm{~m}, 1 \mathrm{H}, \mathrm{CHH}), 0.96\left(\mathrm{~d}, 6 \mathrm{H}, J=2.1 \mathrm{~Hz}, 2 \times \mathrm{CH}_{3}\right), 0.90(\mathrm{t}, 3 \mathrm{H}$, $\left.J=7.2 \mathrm{~Hz}, \mathrm{CH}_{3}\right) ;{ }^{13} \mathrm{C}-\mathrm{NMR}\left(150 \mathrm{MHz}, \mathrm{CDCl}_{3}\right) \delta 173.5,169.4,161.8,160.2,139.4,127.8,115.9,71.5$, 54.9, 51.6, 35.7, 30.1, 27.0, 23.2, 20.7, 19.2, 14.1; HR-MS (ESI) Calcd for $\mathrm{C}_{20} \mathrm{H}_{29} \mathrm{FNO}_{3} 350.2132$, $[\mathrm{M}+\mathrm{H}]^{+}$, found 350.2122 .

3.2.2. 1-(4-Fluorophenyl)-3-alkyl-2-oxopiperidine-3-carboxylic Acids 6a-c were Prepared by a Procedure Similar to that of Compound 3.

3-Methyl-1-(4-fluorophenyl)-2-oxopiperidine-3-carboxylic acid (6a). White solid; 88\% yield; ${ }^{1} \mathrm{H}-\mathrm{NMR}$ $\left(600 \mathrm{MHz}, \mathrm{DMSO}-d_{6}\right) \delta 12.59$ (s, $\left.1 \mathrm{H}, \mathrm{OH}\right), 7.31-7.25$ (m, 2H, ArH), 7.24-7.17 (m, 2H, ArH), 3.65 (dt, $1 \mathrm{H}, J=12.1,6.1 \mathrm{~Hz}, \mathrm{NCHH}), 3.59(\mathrm{dt}, 1 \mathrm{H}, J=11.9,5.8 \mathrm{~Hz}, \mathrm{NCHH}), 2.25-2.18(\mathrm{~m}, 1 \mathrm{H}, \mathrm{CHH})$, 1.95-1.87 (m, 2H, CH $), 1.87-1.80(\mathrm{~m}, 1 \mathrm{H}, \mathrm{CHH}), 1.37\left(\mathrm{~s}, 3 \mathrm{H}, \mathrm{CH}_{3}\right) ;{ }^{13} \mathrm{C}-\mathrm{NMR}\left(150 \mathrm{MHz}, \mathrm{DMSO}-d_{6}\right)$ $\delta 174.9,169.7,160.9,159.3,139.8,128.2,115.6,51.2,50.4,32.8,22.6,19.8$; HR-MS (ESI) Calcd for $\mathrm{C}_{13} \mathrm{H}_{15} \mathrm{FNO}_{3}$ 252.1036, $[\mathrm{M}+\mathrm{H}]^{+}$, found 252.1040. 
3-Ethyl-1-(4-fluorophenyl)-2-oxopiperidine-3-carboxylic acid (6b). white solid; 79\% yield; ${ }^{1} \mathrm{H}-\mathrm{NMR}$ $\left(600 \mathrm{MHz}, \mathrm{DMSO}-d_{6}\right) \delta 12.79$ (s, $\left.1 \mathrm{H}, \mathrm{OH}\right), 7.26-7.23$ (m, 2H, ArH), 7.16-7.12 (m, 2H, ArH), 3.92 (dt, $J=12.7,6.5 \mathrm{~Hz}, 1 \mathrm{H}, \mathrm{NCHH}), 3.74(\mathrm{dt}, J=12.6,6.4 \mathrm{~Hz}, 1 \mathrm{H}, \mathrm{NCHH}), 2.56-2.50(\mathrm{~m}, 1 \mathrm{H}, \mathrm{CHH})$, 2.20 (q, $J=6.7 \mathrm{~Hz}, 1 \mathrm{H}, \mathrm{CHH}), 2.05-2.01(\mathrm{~m}, 1 \mathrm{H}, \mathrm{CHH}), 2.01-1.91(\mathrm{~m}, 2 \mathrm{H}, \mathrm{CHH}), 1.84(\mathrm{dt}, J=12.3$, $7.0 \mathrm{~Hz}, 1 \mathrm{H}, \mathrm{CHH}), 0.71\left(\mathrm{t}, J=6.6 \mathrm{~Hz}, 3 \mathrm{H}, \mathrm{CH}_{3}\right) ;{ }^{13} \mathrm{C}-\mathrm{NMR}\left(150 \mathrm{MHz}, \mathrm{DMSO}-d_{6}\right) \delta 174.8,169.8$, 161.2, 159.6, 139.5, 128.4, 115.8, 51.7, 50.9, 33.6, 29.7, 22.6, 18.8; HR-MS (ESI) Calcd for $\mathrm{C}_{14} \mathrm{H}_{17} \mathrm{FNO}_{3}$ 266.1193, [M+ H] $]^{+}$, found 266.1201.

3-Butyl-1-(4-fluorophenyl)-2-oxopiperidine-3-carboxylic acid (6c). White solid; 84\% yield; ${ }^{1} \mathrm{H}-\mathrm{NMR}$ $\left(600 \mathrm{MHz}, \mathrm{DMSO}-d_{6}\right) \delta 12.66(\mathrm{~s}, 1 \mathrm{H}, \mathrm{OH}), 7.25-7.20(\mathrm{~m}, 2 \mathrm{H}, \mathrm{ArH}), 7.14$ (dd, 2H, J=8.6, 7.0 Hz, ArH), 3.96-3.87 (m, 1H, CHH), 3.78-3.72 (m, 1H, CHH), 2.49-2.42 (m, 1H, CHH), $2.22(\mathrm{dt}, J=19.0,7.5 \mathrm{~Hz}$, 2H, $\mathrm{CH}_{2}$ ), 2.03-1.91 (m, 3H, CHH, $\left.\mathrm{CH}_{2}\right), 1.38-1.21\left(\mathrm{~m}, 4 \mathrm{H}, \mathrm{CH}_{2} \mathrm{CH}_{2}\right), 0.88$ (t, $3 \mathrm{H}, J=6.4 \mathrm{~Hz}, \mathrm{CH}_{3}$ ); ${ }^{13} \mathrm{C}-\mathrm{NMR}\left(150 \mathrm{MHz}, \mathrm{DMSO}-d_{6}\right) \delta 174.7,169.5,161.6,160.0,139.6,127.9,115.6,54.6,51.3,35.4$, 30.3, 23.2, 20.7, 14.2; HR-MS (ESI) Calcd for $\mathrm{C}_{16} \mathrm{H}_{21} \mathrm{FNO}_{3} 294.1506,[\mathrm{M}+\mathrm{H}]^{+}$, found 294.1496.

3,4-Dichloropicolinamide (8). To a solution of 2,2,6,6-tetramethylpiperidine (1.56 g, $11 \mathrm{mmol})$ in dry ether $(20 \mathrm{~mL})$ at $0{ }^{\circ} \mathrm{C}$ was added $n$-BuLi $(4.4 \mathrm{~mL}, 2.5 \mathrm{M}$ in THF, $11 \mathrm{mmol})$ slowly. The reaction mixture was stirred at this temperature for $30 \mathrm{~min}$ before cooled to $-78{ }^{\circ} \mathrm{C}$. A solution of 3,4-dichloropyridine $(1.48 \mathrm{~g}, 10 \mathrm{mmol})$ in dry ether $(5 \mathrm{~mL})$ was injected via syringe to the above reaction mixture and stirred for $2 \mathrm{~h}$ before trimethylsilyl isothiocyanate $(15 \mathrm{mmol})$ was added. After warmed to room temperature, the reaction was quenched by the addition of HOAc $(2 \mathrm{~mL})$ and water $(10 \mathrm{~mL})$, and then let to stir overnight. The suspension was filtered and washed with cold water, giving the title compound as a gray solid (686 mg, 40\%). ${ }^{1} \mathrm{H}-\mathrm{NMR}\left(\mathrm{DMSO}-d_{6}, 600 \mathrm{MHz}\right) \delta 8.50(\mathrm{~d}, 1 \mathrm{H}$, $J=5.2 \mathrm{~Hz}, \mathrm{ArH}), 8.12$ (br s, $1 \mathrm{H}, \mathrm{CONH}_{2}$ ), 7.83 (d, $\left.1 \mathrm{H}, J=5.2 \mathrm{~Hz}, \mathrm{ArH}\right), 7.82$ (br s, $1 \mathrm{H}, \mathrm{CONH}_{2}$ ).

4-(4-Amino-2-fluorophenoxy)-3-chloropicolinamide (9). To a solution of 4-amino-2-fluorophenol (465 mg, $3.65 \mathrm{mmol})$ in DMF $(10 \mathrm{~mL})$ was added potassium tert-butoxide $(440 \mathrm{mg}, 3.95 \mathrm{mmol})$. Thirty min later, 3,4-dichloropicolinamide (8) was added and the solution was heated to $50{ }^{\circ} \mathrm{C}$. When TLC showed all the starting materials consumed, the reaction mixture was diluted with EtOAc $(50 \mathrm{~mL})$, washed with saturated $\mathrm{NaHCO}_{3}$, brine, and dried over $\mathrm{Na}_{2} \mathrm{SO}_{4}$. After concentration, the residue was purified by column chromatography giving the title compound as a pale yellow solid (580 $\mathrm{mg}, 79 \%$ ). ${ }^{1} \mathrm{H}-\mathrm{NMR}\left(\mathrm{DMSO}-d_{6}, 600 \mathrm{MHz}\right) \delta 8.29(\mathrm{~d}, 1 \mathrm{H}, J=5.6 \mathrm{~Hz}, \mathrm{ArH}), 7.00$ (t, $\left.1 \mathrm{H}, J=8.8 \mathrm{~Hz}, \mathrm{ArH}\right), 6.79$ $(\mathrm{d}, 1 \mathrm{H}, J=5.6 \mathrm{~Hz}, \mathrm{ArH}), 6.63-6.55(\mathrm{~m}, 2 \mathrm{H}, \mathrm{ArH}) ;{ }^{13} \mathrm{C}-\mathrm{NMR}$ (DMSO-d $\left.6,150 \mathrm{MHz}\right) \delta 166.6,160.8$, 154.1, 153.9, 149.0, 148.7, 128.5, 123.7, 115.9, 110.1, 110.0, 101.3.

4-((7H-Pyrrolo[2,3-d]pyrimidin-4-yl)oxy)-3-fluoroaniline (11). The solution of 4-chloro-7H-pyrrolo[2,3-d]pyrimidine (1.0 g, $6.5 \mathrm{mmol})$ and 2-fluoro-4-nitrophenol $(1.5 \mathrm{~g}, 9.5 \mathrm{mmol})$ in bromobenzene $(5 \mathrm{~mL})$ was heated at $130{ }^{\circ} \mathrm{C}$ for $4 \mathrm{~h}$ in a sealed tube. After that, the reaction mixture was cooled to room temperature, diluted with $\mathrm{Et}_{2} \mathrm{O}(5 \mathrm{~mL})$ and filtered. Recrystallization in $\mathrm{MeOH}$ gave 4-(2-fluoro-4nitrophenoxy)-7H-pyrrolo[2,3- $d$ ] pyrimidine as a yellow solid (1.6 g, 85\%), which was used for the next step directly. To a solution of this nitro compound in THF $(5 \mathrm{~mL})$ and $\mathrm{MeOH}(5 \mathrm{~mL})$ was added zinc powder $(130 \mathrm{mg}, 2 \mathrm{mmol})$ and $\mathrm{NH}_{4} \mathrm{Cl}(270 \mathrm{mg}, 5 \mathrm{mmol})$. The reaction mixture was stirred at room temperature for $5 \mathrm{~h}$ before filtered through a Celite pad. The filtrate was diluted with EtOAc, washed 
with water, dried over $\mathrm{Na}_{2} \mathrm{SO}_{4}$ and concentrated. The residue was purified by column chromatography giving compound 11 (115 mg, 69\%) as a brown solid. ${ }^{1} \mathrm{H}-\mathrm{NMR}\left(600 \mathrm{MHz}, \mathrm{DMSO}-d_{\text {) }} \delta 12.19(\mathrm{~s}, 1 \mathrm{H}\right.$, $\mathrm{NH}), 8.28(\mathrm{~s}, 1 \mathrm{H}, \mathrm{CH}), 7.44(\mathrm{t}, 1 \mathrm{H}, J=3.1 \mathrm{~Hz}, \mathrm{ArH}), 7.00$ (t, 1H, $J=8.9 \mathrm{~Hz}, \mathrm{ArH}), 6.48$ (dd, 1H, $J=13.0$, $2.6 \mathrm{~Hz}, \mathrm{ArH}), 6.45(\mathrm{dd}, 1 \mathrm{H}, J=3.4,1.5 \mathrm{~Hz}, \mathrm{CH}), 6.42-6.39(\mathrm{~m}, 1 \mathrm{H}, \mathrm{CH}), 5.35\left(\mathrm{~s}, 2 \mathrm{H}, \mathrm{NH}_{2}\right)$.

2-Chloro-4-(2-fluoro-4-nitrophenoxy)pyrimidine (12). 2-Fluoro-4-nitrophenol (314 mg, $2 \mathrm{mmol}), \mathrm{K}_{2} \mathrm{CO}_{3}$ (304 mg, $2.2 \mathrm{mmoo}$ ) and 2,4-dichloropyrimidine (300 mg, $2 \mathrm{mmol}$ ) were dissolved in DMF (20 mL) and heated at $100{ }^{\circ} \mathrm{C}$ for $2 \mathrm{~h}$. the reaction mixture was concentrated, diluted with EtOAc $(100 \mathrm{~mL})$, washed with water, brine, and concentrated in vacuo. The residue was purified by column chromatography giving compound $12(324 \mathrm{mg}, 65 \%)$ as a white solid. ${ }^{1} \mathrm{H}-\mathrm{NMR}\left(600 \mathrm{MHz}, \mathrm{DMSO}-d_{6}\right) \delta 8.78(\mathrm{~d}$, $J=5.7 \mathrm{~Hz}, 1 \mathrm{H}, \mathrm{ArH}), 8.44(\mathrm{dd}, 1 \mathrm{H} J=10.2,2.7 \mathrm{~Hz}, \mathrm{ArH}), 8.25$ (ddd, $1 \mathrm{H}, J=9.0,2.7,1.3 \mathrm{~Hz}, \mathrm{ArH})$, $7.82(\mathrm{dd}, 1 \mathrm{H}, J=9.0,7.7 \mathrm{~Hz}, \operatorname{ArH}), 7.49(\mathrm{~d}, 1 \mathrm{H}, J=5.7 \mathrm{~Hz}, \mathrm{ArH})$.

4-(4-Amino-2-fluorophenoxy)-N-(4-methoxybenzyl)pyrimidin-2-amine (13). To the solution of compound 12 (239 mg 1 mmol) and 4-methoxybenzylamine (192 mg, $1.4 \mathrm{mmol})$ in DMF $(8 \mathrm{~mL})$ was added $\mathrm{K}_{2} \mathrm{CO}_{3}(152 \mathrm{mg}, 1.1 \mathrm{mmol})$. The reaction mixture was heated at $100{ }^{\circ} \mathrm{C}$ for $1 \mathrm{~h}$ before concentrated in vacuo. After diluted with EtOAc, the solution was washed with water and brine, and then concentrated. The residue was purified by column chromatography giving a yellow solid (231 mg, 68\%), which was treated by zinc powder and $\mathrm{NH}_{4} \mathrm{Cl}$ as described for the preparation of compound 11. After workup and purification, compound 13 was obtained as a brown solid $(115 \mathrm{mg}, 69 \%) .{ }^{1} \mathrm{H}-\mathrm{NMR}\left(600 \mathrm{MHz}, \mathrm{CDCl}_{3}\right)$ $\delta 8.06$ (br s, 1H, ArH), 7.12 (br s, 2H, ArH), 6.92 (t, $1 \mathrm{H}, J=8.6 \mathrm{~Hz}, \mathrm{ArH}), 6.80$ (d, 2H, $J=8.2 \mathrm{~Hz}$, ArH), 6.47 (dd, 1H, $J=11.8,2.7 \mathrm{~Hz}, \mathrm{ArH}), 6.45-6.39$ (m, 1H, ArH), 6.15 (d, 1H, J=5.8 Hz, ArH), 4.36 (br s, $2 \mathrm{H}, \mathrm{NH}_{2}$ ), 3.92 (br s, $\left.2 \mathrm{H}, \mathrm{CH}_{2}\right), 3.78\left(\mathrm{~s}, 3 \mathrm{H}, \mathrm{CH}_{3}\right)$.

4-((6,7-Dimethoxyquinolin-4-yl)oxy)-3-fluoroaniline (14). The procedure used was similar to that used for the synthesis of compound 11. Compound $\mathbf{1 4}$ was obtained as a brown solid in 76\% yield. ${ }^{1} \mathrm{H}-\mathrm{NMR}\left(600 \mathrm{MHz}, \mathrm{CDCl}_{3}\right) \delta 8.47(\mathrm{~d}, 1 \mathrm{H}, J=5.1 \mathrm{~Hz}, \mathrm{ArH}), 7.58(\mathrm{~s}, 1 \mathrm{H}, \mathrm{ArH}), 7.40$ (s, 1H, ArH), 7.02 (t, 1H, $J=8.6 \mathrm{~Hz}, \mathrm{ArH}), 6.55$ (dd, 1H, $J=12.0,2.7 \mathrm{~Hz}, \mathrm{ArH}), 6.49$ (dd, 1H, $J=8.9,2.6 \mathrm{~Hz}, \mathrm{ArH}$ ), $6.40(\mathrm{~d}, 1 \mathrm{H}, J=5.0 \mathrm{~Hz}, \mathrm{ArH}), 4.05\left(\mathrm{~s}, 3 \mathrm{H}, \mathrm{OCH}_{3}\right), 4.03\left(\mathrm{~s}, 3 \mathrm{H}, \mathrm{OCH}_{3}\right), 3.84\left(\mathrm{br} \mathrm{s}, 2 \mathrm{H}, \mathrm{NH}_{2}\right)$.

\subsubsection{General Procedure for the Preparation of $15 \mathbf{a}-\mathbf{b}, \mathbf{1 7} \mathbf{a}-\mathbf{b}, \mathbf{1 8 a}-\mathbf{b}$ and $\mathbf{2 0 a}-\mathbf{b}$}

EDC-HCl (1.2 g, $6.25 \mathrm{mmol})$ was added to a suspension of the carboxylic acid $(2.5 \mathrm{~mol}$ of $\mathbf{3}, \mathbf{4}$, or 6a-c) and the amine $\left(2.5 \mathrm{mmol}\right.$ of $\mathbf{9}, \mathbf{1 1}, 13$ or 14) in THF $(25 \mathrm{~mL})$ at $0{ }^{\circ} \mathrm{C}$ followed by DMAP $(30 \mathrm{mg}$, $0.25 \mathrm{mmol})$. The reaction mixture was warmed to room temperature and stirred overnight. After diluted with EtOAc $(150 \mathrm{~mL})$, the whole mixture was washed with $1 \mathrm{M} \mathrm{HCl}(3 \times 10 \mathrm{~mL}), 5 \%$ $\mathrm{NaHCO}_{3}(3 \times 10 \mathrm{~mL})$, and brine $(3 \times 10 \mathrm{~mL})$, dried over $\mathrm{Na}_{2} \mathrm{SO}_{4}$, and concentrated in vacuo. The residue was purified by column chromatography to give corresponding amide.

3-Chloro-4-(2-fluoro-4-(1-(4-fluorophenyl)-2-oxopiperidine-3-carboxamido)phenoxy)picolinamide (15a, from 9 and 3): 76\% yield; ${ }^{1} \mathrm{H}-\mathrm{NMR}\left(600 \mathrm{MHz}, \mathrm{DMSO}-d_{6}\right) \delta 10.56(\mathrm{~s}, 1 \mathrm{H}, \mathrm{NH}), 8.33(\mathrm{~d}, 1 \mathrm{H}$, $J=5.5 \mathrm{~Hz}, \mathrm{ArH}), 8.07(\mathrm{~s}, 1 \mathrm{H}, \mathrm{NH}), 7.91(\mathrm{dd}, 1 \mathrm{H}, J=12.9,2.4 \mathrm{~Hz}, \mathrm{ArH}), 7.77$ (s, 1H, NH), 7.44 (dd, $1 \mathrm{H}, J=8.9,2.4 \mathrm{~Hz}, \mathrm{ArH}), 7.41(\mathrm{t}, 1 \mathrm{H}, J=8.8 \mathrm{~Hz}, \mathrm{ArH}), 7.36-7.32$ (m, 2H, ArH), 7.26-7.20 (m, 2H, 
ArH), $6.84(\mathrm{dd}, 1 \mathrm{H}, J=5.5,1.1 \mathrm{~Hz}, \mathrm{ArH}), 3.76-3.68(\mathrm{~m}, 1 \mathrm{H}, \mathrm{CH}), 3.65-3.57\left(\mathrm{~m}, 2 \mathrm{H}, \mathrm{CH}_{2}\right), 2.21-2.13$ $\left(\mathrm{m}, 2 \mathrm{H}, \mathrm{CH}_{2}\right), 2.12-2.04(\mathrm{~m}, 1 \mathrm{H}, \mathrm{CHH}), 1.96-1.87(\mathrm{~m}, 1 \mathrm{H}, \mathrm{CHH}) ;{ }^{13} \mathrm{C}-\mathrm{NMR}\left(150 \mathrm{MHz}, \mathrm{DMSO}-d_{6}\right) \delta$ $169.3,166.5,160.9,160.0,159.3,154.2,153.8,152.2,148.7,139.4,138.5,138.4,134.8,134.7,128.3$, 128.2, 123.7, 116.3, 115.9, 115.6, 115.4, 110.6, 107.9, 107.8, 54.9, 51.2, 50.5, 48.6, 24.8, 21.2; MS (ESI pos ion) $m / z$ : calcd for $\mathrm{C}_{24} \mathrm{H}_{19} \mathrm{ClF}_{2} \mathrm{~N}_{4} \mathrm{O}_{4} 500.1$, found $501.1[\mathrm{M}+\mathrm{H}]^{+}$; HR-MS (ESI) Calcd for $\mathrm{C}_{24} \mathrm{H}_{20} \mathrm{ClF}_{2} \mathrm{~N}_{4} \mathrm{O}_{4} 501.1141[\mathrm{M}+\mathrm{H}]^{+}$, found 501.1160 .

3-Chloro-4-(4-(3-chloro-1-(4-fluorophenyl)-2-oxopiperidine-3-carboxamido)-2-fluorophenoxy)picolinamide (15b, from 9 and 4) 68\% yield; ${ }^{1} \mathrm{H}-\mathrm{NMR}\left(600 \mathrm{MHz}, \mathrm{CDCl}_{3}\right) \delta 10.11(\mathrm{~s}, 1 \mathrm{H}, \mathrm{NH}), 8.24$ (d, $1 \mathrm{H}, J=5.5 \mathrm{~Hz}, \mathrm{ArH}), 7.80$ (dd, $1 \mathrm{H}, J=11.9,2.5 \mathrm{~Hz}, \mathrm{ArH}), 7.54$ (d, 1H, $J=3.9 \mathrm{~Hz}, \mathrm{ArH}), 7.33-7.22$ (m, 3H, ArH), 7.18-7.11 (m, 3H, NH), $6.68(\mathrm{dd}, 1 \mathrm{H}, J=5.5,1.1 \mathrm{~Hz}, \mathrm{ArH}), 6.15(\mathrm{~d}, 1 \mathrm{H}, J=3.4 \mathrm{~Hz}$, ArH), 3.85-3.78 (m, 1H, CHH), 3.73-3.68 (m, 1H, CHH), 2.96-2.87 (m, 1H, CHH), 2.65-2.56 (m, $1 \mathrm{H}, \mathrm{CHH}), 2.45-2.34(\mathrm{~m}, 1 \mathrm{H}, \mathrm{CHH}), 2.17-2.07(\mathrm{~m}, 1 \mathrm{H}, \mathrm{CHH}) ;{ }^{13} \mathrm{C}-\mathrm{NMR}\left(150 \mathrm{MHz}, \mathrm{CDCl}_{3}\right) \delta 166.8$, 166.0, 164.9, 162.6, 161.8, 160.9, 154.7, 153.0, 148.3, 147.0, 137.9, 136.8, 136.8, 136.8, 127.9, 127.8, $123.4,121.2,116.7,116.6,116.5,111.7,109.8,109.6,64.4,52.6,33.8,19.4$; MS (ESI pos ion) $\mathrm{m} / z$ : calcd for $\mathrm{C}_{24} \mathrm{H}_{18} \mathrm{Cl}_{2} \mathrm{~F}_{2} \mathrm{~N}_{4} \mathrm{O}_{4} 534.1$ found $535.1[\mathrm{M}+\mathrm{H}]^{+}$; HR-MS (ESI) Calcd for $\mathrm{C}_{24} \mathrm{H}_{19} \mathrm{Cl}_{2} \mathrm{~F}_{2} \mathrm{~N}_{4} \mathrm{O}_{4}$ $535.0752[\mathrm{M}+\mathrm{H}]^{+}$, found 535.0764 .

$\mathrm{N}$-(4-((7H-pyrrolo[2,3-d]pyrimidin-4-yl)oxy)-3-fluorophenyl)-1-(4-fluorophenyl)-2-oxopiperidine-3carboxamide (17a, from 11 and 3): 31\% yield, ${ }^{1} \mathrm{H}-\mathrm{NMR}\left(600 \mathrm{MHz}, \mathrm{CDCl}_{3}\right) \delta 11.02(\mathrm{~s}, 1 \mathrm{H}, \mathrm{NH}), 10.19$ (s, 1H, NH), 8.87 (s, 1H, ArH), 8.54 (s, 1H, ArH), 8.13-7.93 (m, 1H, ArH), $7.81(\mathrm{~d}, 1 \mathrm{H}, J=11.6 \mathrm{~Hz}$, ArH), 7.42 (s, 1H, ArH), 7.31-7.20 (m, 2H, ArH), 7.16-7.03 (m, 2H, ArH), 6.92 (s, 1H, ArH), 3.74-3.59 (m, 2H, NCH ), 3.59-3.47 (m, 1H, CH), 2.63-2.51 (m, 1H, CHH), 2.26-2.16 (m, $1 \mathrm{H}, \mathrm{CH}), 2.15-2.07$ (m, $1 \mathrm{H}, \mathrm{CHH}), 2.08-1.98(\mathrm{~m}, 1 \mathrm{H}, \mathrm{CHH}) ;{ }^{13} \mathrm{C}-\mathrm{NMR}\left(150 \mathrm{MHz}, \mathrm{CDCl}_{3}\right) \delta 169.5,168.3,162.5,160.9$, $156.2,155.9,154.6,152.4,151.1,139.8,138.5,134.5,134.2,128.2,128.1,126.2,123.0,116.9,116.8$, 116.7, 116.6, 115.8, 115.6, 109.4, 109.2, 100.3, 53.1, 47.8, 47.7, 29.7, 22.8, 21.6; MS (ESI pos ion) $m / z$ : calcd for $\mathrm{C}_{24} \mathrm{H}_{19} \mathrm{~F}_{2} \mathrm{~N}_{5} \mathrm{O}_{3} 463.1$, found $464.2[\mathrm{M}+\mathrm{H}]^{+}$; HR-MS (ESI) Calcd for $\mathrm{C}_{24} \mathrm{H}_{20} \mathrm{~F}_{2} \mathrm{~N}_{5} \mathrm{O}_{3}$ $464.1534[\mathrm{M}+\mathrm{H}]^{+}$, found 464.1547 .

$\mathrm{N}$-(4-((7H-pyrrolo[2,3-d] pyrimidin-4-yl)oxy)-3-fluorophenyl)-3-chloro-1-(4-fluorophenyl)-2-oxopiperidine-3-carboxamide (17b, from 11 and 4): 42\% yield; ${ }^{1} \mathrm{H}-\mathrm{NMR}\left(600 \mathrm{MHz}, \mathrm{CDCl}_{3}\right) \delta 8.25$ (s, $1 \mathrm{H}, \mathrm{ArH}), 7.89$ (dd, $J=12.5,2.5 \mathrm{~Hz}, 1 \mathrm{H}, \mathrm{ArH}), 7.50$ (d, $J=3.6 \mathrm{~Hz}, 1 \mathrm{H}, \mathrm{ArH}), 7.48$ (dd, $J=2.5,1.3 \mathrm{~Hz}$, 1H, ArH), 7.46-7.42 (m, 3H, ArH), 7.38 (t, $J=8.7 \mathrm{~Hz}, 1 \mathrm{H}, \mathrm{ArH}), 7.25-7.19$ (m, 2H, ArH), 6.64 (d, $J=3.6 \mathrm{~Hz}, 1 \mathrm{H}, \mathrm{ArH}), 3.98-3.88(\mathrm{~m}, 1 \mathrm{H} . \mathrm{CHH}), 3.84-3.78(\mathrm{~m}, 1 \mathrm{H} . \mathrm{CHH}), 2.96$ (ddd, $J=14.8,11.6$, $3.2 \mathrm{~Hz}, 1 \mathrm{H}$. CHH), 2.59-2.52 (m, 1H. CHH), 2.40-2.31 (m, 1H. CHH), 2.21-2.11 (m, 1H. CHH); ${ }^{13} \mathrm{C}-\mathrm{NMR}\left(150 \mathrm{MHz}, \mathrm{CDCl}_{3}\right) \delta 169.7,168.5,162.7,160.9,156.3,155.9,154.7,152.4,151.3,139.8$, 138.6, 134.7, 134.5, 128.4, 128.3, 126.4, 123.6, 117.0, 116.8, 116.7, 116.6, 115.9, 115.7, 109.6, 109.4, 100.6, 64.5, 53.5, 47.9, 47.7, 29.9, 22.8, 21.8; MS (ESI pos ion) $m / z$ : calcd for $\mathrm{C}_{24} \mathrm{H}_{18} \mathrm{ClF}_{2} \mathrm{~N}_{5} \mathrm{O}_{3} 497.1$, found $498.0[\mathrm{M}+\mathrm{H}]^{+}$; HR-MS (ESI) Calcd for $\mathrm{C}_{24} \mathrm{H}_{19} \mathrm{ClF}_{2} \mathrm{~N}_{5} \mathrm{O}_{3} 498.1145[\mathrm{M}+\mathrm{H}]^{+}$, found 498.1155 .

N-(3-fluoro-4-((2-((4-methoxybenzyl)amino)pyrimidin-4-yl)oxy)phenyl)-1-(4-fluorophenyl)-2-oxopiperidine-3-carboxamide (18a, from 13 and 3): 69\% yield, ${ }^{1} \mathrm{H}-\mathrm{NMR}\left(600 \mathrm{MHz}, \mathrm{CDCl}_{3}\right) \delta 10.19$ (s, $1 \mathrm{H}, \mathrm{NH}), 8.06$ (s, 1H, ArH), $7.75(\mathrm{~d}, 1 \mathrm{H}, J=12.2 \mathrm{~Hz}, \operatorname{ArH}), 7.24-7.18$ (m, 3H, ArH), 7.11 (t, 2H, 
$J=8.3 \mathrm{~Hz}, \mathrm{ArH}), 7.06$ (t, 1H, $J=8.4 \mathrm{~Hz}, \mathrm{ArH}), 7.00$ (d, 1H, $J=8.6 \mathrm{~Hz}, \mathrm{ArH}), 6.78(\mathrm{~s}, 2 \mathrm{H}, \mathrm{ArH}), 6.23$ (s, $1 \mathrm{H}, \operatorname{ArH}), 4.24\left(\mathrm{~s}, 2 \mathrm{H}, \mathrm{CH}_{2}\right), 3.76\left(\mathrm{~s}, 3 \mathrm{H}, \mathrm{OCH}_{3}\right), 3.71-3.62\left(\mathrm{~m}, 2 \mathrm{H}, \mathrm{NCH}_{2}\right), 3.62-3.57(\mathrm{~m}, 1 \mathrm{H}$, $\mathrm{CH}), 2.58-2.48(\mathrm{~m}, 1 \mathrm{H}, \mathrm{CHH}), 2.25-2.14(\mathrm{~m}, 1 \mathrm{H}, \mathrm{CHH}), 2.13-2.05(\mathrm{~m}, 1 \mathrm{H}, \mathrm{CHH}), 2.05-1.97(\mathrm{~m}, 1 \mathrm{H}$, $\mathrm{CHH}) ;{ }^{13} \mathrm{C}-\mathrm{NMR}\left(150 \mathrm{MHz}, \mathrm{CDCl}_{3}\right) \delta 169.3,166.0,162.4,160.8,159.0,156.7,154.8,138.4,129.3$, $128.2,128.1,123.7,116.6,116.5,115.3,114.0,55.4,52.7,47.7,22.9,21.7$; MS (ESI pos ion) $\mathrm{m} / z$ : calcd for $\mathrm{C}_{30} \mathrm{H}_{27} \mathrm{~F}_{2} \mathrm{~N}_{5} \mathrm{O}_{4}$ 559.2, found $560.2[\mathrm{M}+\mathrm{H}]^{+}$; HR-MS (ESI) Calcd for $\mathrm{C}_{30} \mathrm{H}_{28} \mathrm{~F}_{2} \mathrm{~N}_{5} \mathrm{O}_{4}$ $560.2109[\mathrm{M}+\mathrm{H}]^{+}$, found 560.2125 .

\section{3-Chloro-N-(3-fluoro-4-((2-((4-methoxybenzyl)amino)pyrimidin-4-yl)oxy)phenyl)-1-(4-fluorophenyl)-}

2-oxopiperidine-3-carboxamide (18b, from 13 and 4):57\% yield; ${ }^{1} \mathrm{H}-\mathrm{NMR}\left(600 \mathrm{MHz}, \mathrm{CDCl}_{3}\right) \delta 9.96$ (s, 1H, NH), 8.12 (s, 1H, ArH), 7.69 (dd, $J=11.8,2.5$ Hz, 1H, ArH), 7.25-7.22 (m, 2H, ArH), 7.19 (dd, $1 \mathrm{H}, J=8.9,2.4 \mathrm{~Hz}, \operatorname{ArH}), 7.15-7.08$ (m, 4H, ArH), 6.80 (d, 2H, $J=8.0 \mathrm{~Hz}, \operatorname{ArH}), 6.18(\mathrm{~d}, 1 \mathrm{H}$, $J=5.7 \mathrm{~Hz}, \mathrm{ArH}), 4.32\left(\mathrm{~s}, 2 \mathrm{H}, \mathrm{CH}_{2}\right), 3.81-3.75(\mathrm{~m}, 1 \mathrm{H}, \mathrm{CHH}), 3.77\left(\mathrm{~s}, 3 \mathrm{H}, \mathrm{OCH}_{3}\right), 3.69$ (dt, $1 \mathrm{H}, J=12.4$, $4.9 \mathrm{~Hz}, \mathrm{CHH}$ ), 2.90 (ddd, 1H, $J=14.6,11.3,3.0 \mathrm{~Hz}, \mathrm{CHH}), 2.63-2.54$ (m, 1H, CHH), 2.41-2.31 (m, $1 \mathrm{H}, \mathrm{CHH}), 2.15-2.06(\mathrm{~m}, 1 \mathrm{H}, \mathrm{CHH}) ;{ }^{13} \mathrm{C}-\mathrm{NMR}\left(150 \mathrm{MHz}, \mathrm{CDCl}_{3}\right) \delta 166.9,164.6,162.6,162.1$, $160.9,159.5,158.9,157.7,155.3,153.70,138.0,136.4,136.3,135.8,135.8,130.9,129.1,127.9$, 127.8, 124.2, 116.7, 116.5, 115.7, 113.9, 64.4, 55.4, 55.3, 52.7, 45.0, 33.9, 19.5; MS (ESI pos ion) m/z: calcd for $\mathrm{C}_{30} \mathrm{H}_{26} \mathrm{ClF}_{2} \mathrm{~N}_{5} \mathrm{O}_{4}$ 593.2, found $594.2[\mathrm{M}+\mathrm{H}]^{+}$; HR-MS (ESI) Calcd for $\mathrm{C}_{30} \mathrm{H}_{27} \mathrm{ClF}_{2} \mathrm{~N}_{5} \mathrm{O}_{4}$ $594.1720[\mathrm{M}+\mathrm{H}]^{+}$, found 594.1733.

$\mathrm{N}$-(4-((6,7-dimethoxyquinolin-4-yl)oxy)-3-fluorophenyl)-1-(4-fluorophenyl)-2-oxopiperidine-3-carboxamide (20a, from 14 and 3): 61\% yield; ${ }^{1} \mathrm{H}-\mathrm{NMR}\left(600 \mathrm{MHz}, \mathrm{CDCl}_{3}\right) \delta 10.30(\mathrm{~s}, 1 \mathrm{H}, \mathrm{NH}), 8.51(\mathrm{~s}, 1 \mathrm{H}$, ArH), 7.84 (dd, 1H, $J=12.1,2.5 \mathrm{~Hz}, \operatorname{ArH}), 7.69$ (s, 1H, ArH), 7.59 (s, 1H, ArH), 7.29-7.26 (m, 1H, ArH), 7.25-7.21 (m, 2H, ArH), 7.18 (t, 1H, $J=8.6 \mathrm{~Hz}, \mathrm{ArH}), 7.12$ (t, 2H, $J=8.5 \mathrm{~Hz}, \mathrm{ArH}), 6.49$ (d, $1 \mathrm{H}, J=5.5 \mathrm{~Hz}, \mathrm{ArH}), 4.08\left(\mathrm{~s}, 3 \mathrm{H}, \mathrm{OCH}_{3}\right), 4.06\left(\mathrm{~s}, 3 \mathrm{H}, \mathrm{OCH}_{3}\right), 3.75-3.60(\mathrm{~m}, 2 \mathrm{H}, \mathrm{CHH}), 3.58-3.49$ (m, 1H, CH), 2.60-2.47 (m, 1H, CHH), 2.29-2.19 (m, 1H, CHH), 2.14-1.97 (m, 2H, $\left.\mathrm{CH}_{2}\right)$; ${ }^{13} \mathrm{C}-\mathrm{NMR}$ $\left(150 \mathrm{MHz} \mathrm{CDCl}_{3}\right) \delta 169.3,166.4,154.6,150.6,145.7,138.4,128.1,123.5,116.6,116.5,116.2,99.7$, 56.7, 56.4, 52.7, 47.8, 29.8, 23.0, 22.8, 21.7; MS (ESI pos ion) $\mathrm{m} / \mathrm{z}$ : calcd for $\mathrm{C}_{29} \mathrm{H}_{25} \mathrm{~F}_{2} \mathrm{~N}_{3} \mathrm{O}_{5} 533.2$, found $534.2[\mathrm{M}+\mathrm{H}]^{+}$; HR-MS (ESI) Calcd for $\mathrm{C}_{29} \mathrm{H}_{26} \mathrm{~F}_{2} \mathrm{~N}_{3} \mathrm{O}_{5} 534.1841[\mathrm{M}+\mathrm{H}]^{+}$, found 534.1850.

3-Chloro-N-(4-((6,7-dimethoxyquinolin-4-yl)oxy)-3-fluorophenyl)-1-(4-fluorophenyl)-2-oxopiperidine3-carboxamide (20b, from 14 and 4): 54\% yield; ${ }^{1} \mathrm{H}-\mathrm{NMR}\left(600 \mathrm{MHz}, \mathrm{CDCl}_{3}\right) \delta 10.05$ (s, $\left.1 \mathrm{H}, \mathrm{NH}\right)$, $8.48(\mathrm{~d}, 1 \mathrm{H}, J=5.4 \mathrm{~Hz}, \mathrm{ArH}), 7.79$ (dd, $1 \mathrm{H}, J=12.0,2.5 \mathrm{~Hz}, \operatorname{ArH}), 7.57$ (s, 1H, ArH), 7.44 (s, 1H, ArH), 7.29-7.23 (m, 4H, ArH), 7.20 (t, 1H, $J=8.6 \mathrm{~Hz}, \mathrm{ArH}), 7.13$ (t, 2H, J=8.4 Hz, ArH), 6.39 (d, $1 \mathrm{H}, J=5.3 \mathrm{~Hz}, \mathrm{ArH}), 4.05\left(\mathrm{~s}, 3 \mathrm{H}, \mathrm{OCH}_{3}\right), 4.04\left(\mathrm{~s}, 3 \mathrm{H}, \mathrm{OCH}_{3}\right), 3.80(\mathrm{ddd}, 1 \mathrm{H}, J=14.5,10.3,4.7 \mathrm{~Hz}$, $\mathrm{CH} H), 3.74-3.66(\mathrm{~m}, 1 \mathrm{H}, \mathrm{CHH}), 2.97-2.83(\mathrm{~m}, 1 \mathrm{H}, \mathrm{CHH}), 2.67-2.56(\mathrm{~m}, 1 \mathrm{H}, \mathrm{CHH}), 2.45-2.34(\mathrm{~m}$, $1 \mathrm{H}, \mathrm{CHH}), 2.15-2.07(\mathrm{~m}, 1 \mathrm{H}, \mathrm{CHH}) ;{ }^{13} \mathrm{C}-\mathrm{NMR}\left(150 \mathrm{MHz}, \mathrm{CDCl}_{3}\right) \delta 166.9,164.8,162.6,161.0$, 160.2 , 155.3, 153.6, 153.1, 149.8, 148.6, 146.7, 137.9, 137.7, 137.6, 136.3, 136.2, 127.9, 127.8, 123.8, 116.6, 116.5, 116.4, 115.6, 113.0, 109.8, 109.7, 109.6, 109.6, 107.8, 107.74, 99.5, 99.5, 64.3, 56.3, 56.2, 52.7, 33.8, 29.8, 19.5; MS (ESI pos ion) $\mathrm{m} / z$ : calcd for $\mathrm{C}_{29} \mathrm{H}_{24} \mathrm{ClF}_{2} \mathrm{~N}_{3} \mathrm{O}_{5} 567.1$, found $568.1[\mathrm{M}+\mathrm{H}]^{+}$; HR-MS (ESI) Calcd for $\mathrm{C}_{29} \mathrm{H}_{25} \mathrm{ClF}_{2} \mathrm{~N}_{3} \mathrm{O}_{5} 568.1451[\mathrm{M}+\mathrm{H}]^{+}$, found 568.1461. 
$\mathrm{N}$-(4-((6,7-dimethoxyquinolin-4-yl)oxy)-3-fluorophenyl)-1-(4-fluorophenyl)-3-methyl-2-oxopiperidine3-carboxamide (20c, from 14 and 6a): 68\% yield; ${ }^{1} \mathrm{H}-\mathrm{NMR}\left(600 \mathrm{MHz}, \mathrm{CDCl}_{3}\right) \delta 10.01(\mathrm{~s}, 1 \mathrm{H}, \mathrm{NH})$, $8.47(\mathrm{~d}, 1 \mathrm{H}, J=5.3 \mathrm{~Hz}, \operatorname{ArH}), 7.82(\mathrm{dd}, 1 \mathrm{H}, J=12.2,2.5 \mathrm{~Hz}, \operatorname{ArH}), 7.58$ (s, 1H, ArH), 7.42 (s, 1H, ArH), 7.25-7.20 (m, 3H, ArH), $7.19(\mathrm{t}, 1 \mathrm{H}, J=8.5 \mathrm{~Hz}, \mathrm{ArH}), 7.15-7.11(\mathrm{~m}, 2 \mathrm{H}, \mathrm{ArH}), 6.38(\mathrm{~d}, 1 \mathrm{H}$, $J=5.1 \mathrm{~Hz}, \mathrm{ArH}), 4.06\left(\mathrm{~s}, 3 \mathrm{H}, \mathrm{OCH}_{3}\right), 4.04\left(\mathrm{~s}, 3 \mathrm{H}, \mathrm{OCH}_{3}\right), 3.71-3.62\left(\mathrm{~m}, 2 \mathrm{H}, \mathrm{NCH}_{2}\right), 2.83-2.76(\mathrm{~m}$, 1H, $\mathrm{CHH}), 2.07-1.97\left(\mathrm{~m}, 2 \mathrm{H}, \mathrm{CH}_{2}\right), 1.87-1.81(\mathrm{~m}, 1 \mathrm{H}, \mathrm{CHH}), 1.71\left(\mathrm{~s}, 3 \mathrm{H}, \mathrm{CH}_{3}\right) ;{ }^{13} \mathrm{C}-\mathrm{NMR}(150 \mathrm{MHz}$, $\left.\mathrm{CDCl}_{3}\right) \delta 173.7,170.1,162.4,160.8,160.2,153.7,153.0,149.7,148.9,146.9,138.7,137.1,128.2$, $123.8,116.6,116.5,116.0,116.0,115.6,109.2$, 107.9, 102.3, 99.5, 56.3, 56.2, 53.1, 50.5, 30.9, 27.7, 20.7, 14.3; MS (ESI pos ion) $m / z$ : calcd for $\mathrm{C}_{30} \mathrm{H}_{27} \mathrm{~F}_{2} \mathrm{~N}_{3} \mathrm{O}_{5} 547.2$, found $548.2[\mathrm{M}+\mathrm{H}]^{+}$; HR-MS (ESI) Calcd for $\mathrm{C}_{30} \mathrm{H}_{28} \mathrm{~F}_{2} \mathrm{~N}_{3} \mathrm{O}_{5} 548.1997[\mathrm{M}+\mathrm{H}]^{+}$, found 548.2012.

$\mathrm{N}$-(4-((6,7-dimethoxyquinolin-4-yl)oxy)-3-fluorophenyl)-3-ethyl-1-(4-fluorophenyl)-2-oxopiperidine-3carboxamide (20d, from 14 and 6b): 58\% yield; ${ }^{1} \mathrm{H}-\mathrm{NMR}\left(600 \mathrm{MHz}, \mathrm{CDCl}_{3}\right) \delta 9.99(\mathrm{~s}, 1 \mathrm{H}, \mathrm{NH}), 8.47$ (d, 1H, $J=5.4 \mathrm{~Hz}, \mathrm{ArH}), 7.82(\mathrm{dd}, 1 \mathrm{H}, J=12.1,2.4 \mathrm{~Hz}, \mathrm{ArH}), 7.58$ (s, 1H, ArH), 7.44 (s, 1H, ArH), 7.24-7.16 (m, 4H, ArH), 7.15-7.11 (m, 2H, ArH), 6.39 (d, 1H, J=5.2 Hz, ArH), $4.06\left(\mathrm{~s}, 3 \mathrm{H}, \mathrm{OCH}_{3}\right)$, $4.05\left(\mathrm{~s}, 3 \mathrm{H}, \mathrm{OCH}_{3}\right), 3.71-3.59\left(\mathrm{~m}, 2 \mathrm{H}, \mathrm{NCH}_{2}\right), 2.81(1 \mathrm{H}, \mathrm{ddd}, J=13.9,6.4,2.7 \mathrm{~Hz}, \mathrm{CHH}), 2.22-2.14$ (m, 1H, CHH), 2.12-1.93 (m, 4H, $\left.\mathrm{CH}_{2} \mathrm{CH}_{3}\right), 1.82-1.76(\mathrm{~m}, 1 \mathrm{H}, \mathrm{CHH}), 1.02(\mathrm{t}, 3 \mathrm{H}, J=7.4 \mathrm{~Hz}$, $\left.\mathrm{CH}_{2} \mathrm{CH}_{3}\right) ;{ }^{13} \mathrm{C}-\mathrm{NMR}\left(150 \mathrm{MHz}, \mathrm{CDCl}_{3}\right) \delta 173.3,169.0,165.8,162.5,160.4,155.3,153.7,153.1$, 149.7, 148.7, 146.8, 138.8, 137.1, 137.1, 137.0, 136.9, 128.3, 115.7, 107.8, 102.3, 99.6, 56.3, 55.2, 53.1, 33.8, 27.0, 20.8; MS (ESI pos ion) $m / z$ : calcd for $\mathrm{C}_{31} \mathrm{H}_{29} \mathrm{~F}_{2} \mathrm{~N}_{3} \mathrm{O}_{5} 561.2$, found $562.2[\mathrm{M}+\mathrm{H}]^{+}$; HR-MS (ESI) Calcd for $\mathrm{C}_{31} \mathrm{H}_{30} \mathrm{~F}_{2} \mathrm{~N}_{3} \mathrm{O}_{5} 562.2154[\mathrm{M}+\mathrm{H}]^{+}$, found 562.2160.

$\mathrm{N}$-(4-((6,7-dimethoxyquinolin-4-yl)oxy)-3-fluorophenyl)-3-butyl-1-(4-fluorophenyl)-2-oxopiperidine-3carboxamide (20e, from 14 and 6c): 64\% yield; ${ }^{1} \mathrm{H}-\mathrm{NMR}\left(600 \mathrm{MHz}, \mathrm{CDCl}_{3}\right) \delta 9.98(\mathrm{~s}, 1 \mathrm{H}, \mathrm{NH}), 8.47$ (d, 1H, $J=5.4 \mathrm{~Hz}, \mathrm{ArH}), 7.82$ (dd, 1H, $J=12.5,2.6 \mathrm{~Hz}, \mathrm{ArH}), 7.58$ (s, 1H, ArH), 7.42 (s, 1H, ArH), 7.25-7.16 (m, 4H, ArH), 7.16-7.11 (m, 2H, ArH), 6.39 (d, 1H, J=5.1 Hz, ArH), $4.06\left(\mathrm{~s}, 3 \mathrm{H}, \mathrm{OCH}_{3}\right)$, $4.05\left(\mathrm{~s}, 3 \mathrm{H}, \mathrm{OCH}_{3}\right), 3.71-3.59\left(\mathrm{~m}, 2 \mathrm{H}, \mathrm{NCH}_{2}\right), 2.82(\mathrm{ddd}, 1 \mathrm{H}, J=14.0,6.1,2.7 \mathrm{~Hz}, \mathrm{CHH}), 2.13-1.92$ (m, 4H, $\left.2 \times \mathrm{CH}_{2}\right), 1.84-1.77(\mathrm{~m}, 1 \mathrm{H}, \mathrm{CHH}), 1.42-1.28\left(\mathrm{~m}, 4 \mathrm{H}, 2 \times \mathrm{CH}_{2}\right), 0.95-0.89\left(\mathrm{~m}, 3 \mathrm{H}, \mathrm{CH}_{2} \mathrm{CH}_{3}\right)$; ${ }^{13} \mathrm{C}-\mathrm{NMR}\left(150 \mathrm{MHz}, \mathrm{CDCl}_{3}\right) \delta 173.3,169.1,160.3,153.0,149.7,148.9,147.0,138.8,137.1,128.3$, 128.2, 123.8, 116.7, 116.5, 116.0, 115.7, 109.4, 108.0, 102.3, 99.6, 56.3, 56.3, 54.9, 53.1, 40.5, 27.5, 27.0, 23.0, 20.9, 14.1; MS (ESI pos ion) $m / z$ : calcd for $\mathrm{C}_{33} \mathrm{H}_{33} \mathrm{~F}_{2} \mathrm{~N}_{3} \mathrm{O}_{5} 589.2$, found $590.2[\mathrm{M}+\mathrm{H}]^{+}$; HR-MS (ESI) Calcd for $\mathrm{C}_{33} \mathrm{H}_{34} \mathrm{~F}_{2} \mathrm{~N}_{3} \mathrm{O}_{5} 590.2467[\mathrm{M}+\mathrm{H}]^{+}$, found 590.2478.

\subsubsection{Preparation of $\mathbf{1 6 a}$ and $\mathbf{1 6 b}$}

To amide 15a or $\mathbf{1 5 b}(0.2 \mathrm{mmol})$ in ethyl acetate $(2 \mathrm{~mL})$, acetonitrile $(2 \mathrm{~mL})$, and water $(1 \mathrm{~mL})$ at $0{ }^{\circ} \mathrm{C}$ was added iodobenzene diacetate $(82 \mathrm{mg}, 0.26 \mathrm{mmol})$. After stirring at room temperature for $2 \mathrm{~h}$, saturated $\mathrm{NaHCO}_{3}(3 \mathrm{~mL})$ was added, followed by $30 \mathrm{~mL}$ of ethyl acetate. The mixture was filtered, and the filtrate was washed with brine $(3 \times 5 \mathrm{~mL})$, dried over $\mathrm{Na}_{2} \mathrm{SO}_{4}$ and concentrated in vacuo. The residue was purified by flash chromatography on silica gel to give compounds $\mathbf{1 6 a}-\mathbf{b}$.

$\mathrm{N}$-(4-((2-amino-3-chloropyridin-4-yl)oxy)-3-fluorophenyl)-1-(4-fluorophenyl)-2-oxopiperidine-3carboxamide (16a). white solid; yield 72\%; ${ }^{1} \mathrm{H}-\mathrm{NMR}\left(600 \mathrm{MHz}, \mathrm{CDCl}_{3}\right) \delta 10.00(\mathrm{~s}, 1 \mathrm{H}, \mathrm{NH}), 7.71$ 
(dd, $1 \mathrm{H}, J=12.6,2.5 \mathrm{~Hz}, \mathrm{ArH}), 7.24-7.18$ (m, 3H, ArH), 7.17-7.10 (m, 3H, ArH), 7.02 (dt, 1H, $J=9.0$, $1.8 \mathrm{~Hz}, \mathrm{ArH}), 6.62(\mathrm{t}, 1 \mathrm{H}, J=8.9 \mathrm{~Hz}, \mathrm{ArH}), 5.01\left(\mathrm{~s}, 2 \mathrm{H}, \mathrm{NH}_{2}\right), 3.65(\mathrm{dq}, 2 \mathrm{H}, J=7.2,4.3,3.4 \mathrm{~Hz}$, $\left.\mathrm{NCH}_{2}\right), 3.54(\mathrm{t}, J=6.3 \mathrm{~Hz}, 1 \mathrm{H}, \mathrm{CH}), 2.59-2.49(\mathrm{~m}, 1 \mathrm{H}, \mathrm{CHH}), 2.21-2.15(\mathrm{~m}, 1 \mathrm{H}, \mathrm{CHH}), 2.10-2.05$ (m, 1H, CHH), 2.04-1.98 (m, 1H, CHH); ${ }^{13} \mathrm{C}-\mathrm{NMR}\left(150 \mathrm{MHz}, \mathrm{CDCl}_{3}\right)$ 169.4, 165.7, 162.5, 160.9, 155.6, 154.7, 151.1, 146.5, 139.9, 138.5, 134.5, 134.4, 128.2, 128.2, 123.3, 116.9, 116.8, 116.7, 116.6, 116.6, 115.3, 115.2, 109.4, 109.2, 108.9, 52.8, 47.6, 47.5, 29.8, 22.9, 21.8; MS (ESI pos ion) $\mathrm{m} / \mathrm{z}$ : calcd for $\mathrm{C}_{23} \mathrm{H}_{19} \mathrm{ClF}_{2} \mathrm{~N}_{4} \mathrm{O}_{3} 472.1$, found $473.1[\mathrm{M}+\mathrm{H}]^{+}$; HR-MS (ESI) Calcd for $\mathrm{C}_{23} \mathrm{H}_{20} \mathrm{ClF}_{2} \mathrm{~N}_{4} \mathrm{O}_{3} 473.1192$ $[\mathrm{M}+\mathrm{H}]^{+}$, found 473.1214 .

$\mathrm{N}$-(4-((2-amino-3-chloropyridin-4-yl)oxy)-3-fluorophenyl)-3-chloro-1-(4-fluorophenyl)-2-oxo-piperidine3-carboxamide (16b). white solid; yield 76\%; ${ }^{1} \mathrm{H}-\mathrm{NMR}\left(600 \mathrm{MHz}, \mathrm{CDCl}_{3}\right) \delta 10.02(\mathrm{~s}, 1 \mathrm{H}, \mathrm{NH}), 7.77$ (d, $1 \mathrm{H}, J=5.8 \mathrm{~Hz}, \mathrm{ArH}), 7.74(\mathrm{dd}, 1 \mathrm{H}, J=12.0,2.5 \mathrm{~Hz}, \mathrm{ArH}), 7.26-7.23$ (m, 2H, ArH), 7.23-7.20 (m, $1 \mathrm{H}, \operatorname{ArH}), 7.16-7.11(\mathrm{~m}, 3 \mathrm{H}, \mathrm{ArH}), 5.99(\mathrm{dd}, 1 \mathrm{H}, J=5.8,1.0 \mathrm{~Hz}, \mathrm{ArH}), 5.04$ (br s, 2H, NH2), 3.84-3.74 (m, 1H, CHH), 3.74-3.66 (m, 1H, CHH), 2.94-2.82 (m, 1H, CHH), 2.63-2.57 (m, 1H, $\mathrm{CHH}), 2.43-2.34(\mathrm{~m}, 1 \mathrm{H}, \mathrm{CHH}), 2.14-2.09(\mathrm{~m}, 1 \mathrm{H}, \mathrm{CHH}) ;{ }^{13} \mathrm{C}-\mathrm{NMR}\left(150 \mathrm{MHz}, \mathrm{CDCl}_{3}\right) \delta 166.9$, 164.8, 162.6, 161.0, 160.5, 156.6, 155.0, 153.3, 148.6, 147.8, 146.7, 137.9, 136.2, 127.8, 123.4, 116.7, 116.6, 116.2, 109.6, 109.4, 102.6, 102.1, 91.8, 64.2, 52.7, 33.8, 19.5; MS (ESI pos ion) $\mathrm{m} / \mathrm{z}$ : calcd for $\mathrm{C}_{23} \mathrm{H}_{18} \mathrm{Cl}_{2} \mathrm{~F}_{2} \mathrm{~N}_{4} \mathrm{O}_{3}$ 506.1, found 507.1 [M + H] $]^{+}$; HR-MS (ESI) Calcd for $\mathrm{C}_{23} \mathrm{H}_{19} \mathrm{Cl}_{2} \mathrm{~F}_{2} \mathrm{~N}_{4} \mathrm{O}_{3} 507.0802$ $[\mathrm{M}+\mathrm{H}]^{+}$, found 507.0816 .

\subsubsection{Preparation of $19 \mathrm{a}$ and $\mathbf{1 9 b}$}

Compound 18a or $18 \mathrm{~b}$ (40 mg, $0.07 \mathrm{mmol}$ ) was dissolved in TFA and heated to reflux for $6 \mathrm{~h}$. The solvent was removed and the residue was purified by column chromatography, giving the title compound 19a or 19b as a pale yellow solid.

$\mathrm{N}$-(4-((2-aminopyrimidin-4-yl)oxy)-3-fluorophenyl)-1-(4-fluorophenyl)-2-oxopiperidine-3-carboxamide (19a). 71\% yield; ${ }^{1} \mathrm{H}-\mathrm{NMR}\left(600 \mathrm{MHz}, \mathrm{CDCl}_{3}\right) \delta 10.20(\mathrm{~s}, 1 \mathrm{H}, \mathrm{NH}), 7.95(\mathrm{~s}, 1 \mathrm{H}, \mathrm{ArH}), 7.75(\mathrm{~d}$, $1 \mathrm{H}, J=11.8 \mathrm{~Hz}, \mathrm{ArH}), 7.21(\mathrm{dd}, 2 \mathrm{H}, J=8.7,4.8 \mathrm{~Hz}, \mathrm{ArH}), 7.18(\mathrm{~d}, 1 \mathrm{H}, J=8.6 \mathrm{~Hz}, \mathrm{ArH}), 7.13(\mathrm{t}, 2 \mathrm{H}$, $J=8.2 \mathrm{~Hz}, \mathrm{ArH}), 7.07$ (t, 1H, $J=8.4 \mathrm{~Hz}, \mathrm{ArH}), 6.49$ (s, 1H, ArH), 5.77 (s, 1H, NH), 3.67 (q, 2H, $\left.J=6.0 \mathrm{~Hz}, \mathrm{NCH}_{2}\right), 3.57(\mathrm{~s}, 1 \mathrm{H}, \mathrm{CH}), 2.57-2.46(\mathrm{~m}, 1 \mathrm{H}, \mathrm{CHH}), 2.25-2.16(\mathrm{~m}, 1 \mathrm{H}, \mathrm{CHH}), 2.13-1.95$ $\left(\mathrm{m}, 2 \mathrm{H}, \mathrm{CH}_{2}\right) ;{ }^{13} \mathrm{C}-\mathrm{NMR}\left(150 \mathrm{MHz}, \mathrm{CDCl}_{3}\right) \delta 166.3,162.5,160.9,154.4,152.8,138.4,137.8,134.1$, 128.2, 128.1, 123.1, 116.7, 116.5, 115.6, 108.9, 108.7, 52.7, 47.7, 29.8, 23.0, 21.7; MS (ESI pos ion) $m / z$ : calcd for $\mathrm{C}_{22} \mathrm{H}_{19} \mathrm{~F}_{2} \mathrm{~N}_{5} \mathrm{O}_{3} 439.1$, found $440.1[\mathrm{M}+\mathrm{H}]^{+}$; HR-MS (ESI) Calcd for $\mathrm{C}_{22} \mathrm{H}_{20} \mathrm{~F}_{2} \mathrm{~N}_{5} \mathrm{O}_{3}$ $440.1534[\mathrm{M}+\mathrm{H}]^{+}$, found 440.1528 .

$\mathrm{N}$-(4-((2-aminopyrimidin-4-yl)oxy)-3-fluorophenyl)-3-chloro-1-(4-fluorophenyl)-2-oxopiperidine-3carboxamide (19b). 87\% yield; ${ }^{1} \mathrm{H}-\mathrm{NMR}\left(600 \mathrm{MHz}, \mathrm{CDCl}_{3}\right) \delta 10.04(\mathrm{~s}, 1 \mathrm{H}, \mathrm{NH}), 7.96(\mathrm{~d}, 1 \mathrm{H}, J=6.7 \mathrm{~Hz}$, ArH), $7.72(\mathrm{dd}, 1 \mathrm{H}, J=11.8,2.5 \mathrm{~Hz}, \mathrm{ArH}), 7.25-7.18$ (m, 3H, ArH), 7.16-7.06 (m, 3H, ArH), 6.47 (d, $1 \mathrm{H}, J=6.7 \mathrm{~Hz}, \mathrm{ArH}), 3.79(\mathrm{ddd}, 1 \mathrm{H}, J=12.4,10.1,4.7 \mathrm{~Hz}, \mathrm{CHH}), 3.69$ (dt, $1 \mathrm{H}, J=11.3,4.5 \mathrm{~Hz}$, $\mathrm{CHH}), 2.88$ (ddd, $1 \mathrm{H}, J=14.9,11.6,3.1 \mathrm{~Hz}, \mathrm{CHH}), 2.63-2.49$ (m, 1H, CHH), 2.44-2.31 (m, 1H, $\mathrm{CHH}), 2.15-2.05(\mathrm{~m}, 1 \mathrm{H}, \mathrm{CHH}) ;{ }^{13} \mathrm{C}-\mathrm{NMR}\left(150 \mathrm{MHz}, \mathrm{CDCl}_{3}\right) \delta 171.2,166.8,164.9,162.6,161.0$, 154.5, 152.8, 137.9, 137.9, 137.2, 137.1, 134.8, 134.7, 127.9, 127.9, 127.8, 123.3, 116.7, 116.6, 116.0, 
109.3, 109.2, 109.1, 109.1, 100.0, 99.0, 64.4, 52.7, 33.8, 19.4; MS (ESI pos ion) $\mathrm{m} / \mathrm{z}$ : calcd for $\mathrm{C}_{22} \mathrm{H}_{18} \mathrm{ClF}_{2} \mathrm{~N}_{5} \mathrm{O}_{3}$ 473.1, found $474.0[\mathrm{M}+\mathrm{H}]^{+}$; HR-MS (ESI) Calcd for $\mathrm{C}_{22} \mathrm{H}_{19} \mathrm{ClF}_{2} \mathrm{~N}_{5} \mathrm{O}_{3} 474.1145$ $[\mathrm{M}+\mathrm{H}]^{+}$, found 474.1151 .

\subsection{Biology}

\subsection{1. c-Met Kinase Assay}

The effects of indicated compound on the activities of c-Met kinases were determined using enzyme-linked immunosorbent assays (ELISAs) with purified recombinant proteins. Briefly, $20 \mu \mathrm{g} / \mathrm{mL}$ poly (Glu,Tyr) 4:1 (Sigma, St. Louis, MO, USA) was pre-coated in 96-well plates as a substrate. A $50-\mu \mathrm{L}$ aliquot of $10 \mu \mathrm{mol} / \mathrm{L}$ ATP solution diluted in kinase reaction buffer $(50 \mathrm{mmol} / \mathrm{L}$ HEPES [pH 7.4], $50 \mathrm{mmol} / \mathrm{L} \mathrm{MgCl}_{2}, 0.5 \mathrm{mmol} / \mathrm{L} \mathrm{MnCl}_{2}, 0.2 \mathrm{mmol} / \mathrm{L} \mathrm{Na}_{3} \mathrm{VO}_{4}$, and $1 \mathrm{mmol} / \mathrm{L} \mathrm{DTT}$ ) was added to each well; $1 \mu \mathrm{L}$ of various concentrations of indicated compound diluted in $1 \%$ DMSO $(v / v)$ (Sigma) were then added to each reaction well. DMSO $(1 \%, v / v)$ was used as the negative control. The kinase reaction was initiated by the addition of purified c-Met tyrosine kinase proteins diluted in $49 \mu \mathrm{L}$ of kinase reaction buffer. After incubation for $60 \mathrm{~min}$ at $37{ }^{\circ} \mathrm{C}$, the plate was washed three times with phosphate-buffered saline (PBS) containing $0.1 \%$ Tween 20 (T-PBS). Anti-phosphotyrosine (PY99) antibody (100 $\mu \mathrm{L} ; 1: 500$, diluted in $5 \mathrm{mg} / \mathrm{mL}$ BSA T-PBS) was then added. After a 30 -min incubation at $37{ }^{\circ} \mathrm{C}$, the plate was washed three times, and $100 \mu \mathrm{L}$ horseradish peroxidase-conjugated goat anti-mouse IgG (1:2000, diluted in $5 \mathrm{mg} / \mathrm{mL}$ BSA T-PBS) was added. The plate was then incubated at $37{ }^{\circ} \mathrm{C}$ for 30 min and washed 3 times. A $100-\mu \mathrm{L}$ aliquot of a solution containing $0.03 \% \mathrm{H}_{2} \mathrm{O}_{2}$ and $2 \mathrm{mg} / \mathrm{ml} o$-phenylenediamine in $0.1 \mathrm{~mol} / \mathrm{L}$ citrate buffer $(\mathrm{pH} 5.5$ ) was added. The reaction was terminated by the addition of $50 \mu \mathrm{L}$ of $2 \mathrm{~mol} / \mathrm{L} \mathrm{H}_{2} \mathrm{SO}_{4}$ as the color changed, and the plate was analyzed using a multi-well spectrophotometer (SpectraMAX 190, Molecular Devices, Sunnyvale, CA, USA) at $490 \mathrm{~nm}$. The inhibition rate (\%) was calculated using the following equation: $[1-(\mathrm{A} 490 / \mathrm{A} 490$ control $)] \times 100 \%$. The $\mathrm{IC}_{50}$ values were calculated from the inhibition curves in two separate experiments.

\subsubsection{Cell Proliferation Assay}

Cells were seeded in 96-well tissue culture plates. On the next day, the cells were exposed to various concentrations of compounds and further cultured for $72 \mathrm{~h}$. Cell proliferation was then determined using sulforhodamine B (SRB, Sigma, St. Louis, MO, USA). The $\mathrm{IC}_{50}$ values were calculated by concentration-response curve fitting using the four-parameter method.

\section{Conclusions}

In summary, a series of compounds based upon the 3-carboxylpiperidin-2-one scaffold were designed, synthesized and evaluated for their c-Met kinase inhibition and cytotoxicity against MKN45 cancer cell lines. Five compounds $(\mathbf{1 6 b}, \mathbf{2 0 b}-\mathbf{e})$ exhibited moderate to excellent activity against c-Met kinase, with $\mathrm{IC}_{50}$ values ranging from $8.6-81 \mathrm{nM}$. Moreover, four compounds $(\mathbf{2 0 b}-\mathbf{e})$ showed potent inhibitory activity against MKN45 cell proliferation, with $\mathrm{IC}_{50} \mathrm{~s}$ ranging from $0.57-16 \mu \mathrm{M}$. Further structure-activity relationship studies are under way in our laboratory and will be reported in due course. 


\section{Acknowledgments}

This work was supported by the funds from National Program on Key Basic Research Project of China (2012CB910704), the National Natural Science Foundation (91229205, 81102461), and National S\&T Major Projects (2012ZX09301001-007).

\section{Conflicts of Interest}

The authors declare no conflict of interest.

\section{References}

1. Gherardi, E.; Birchmeier, W.; Birchmeier, C.; Vande Woude, G. Targeting MET in cancer: Rationale and progress. Nat. Rev. Cancer 2012, 12, 89-103.

2. Benvenuti, S.; Comoglio, P.M. The MET receptor tyrosine kinase in invasion and metastasis. J. Cell. Physiol. 2007, 213, 316-325.

3. Cappuzzo, F.; Marchetti, A.; Skokan, M.; Rossi, E.; Gajapathy, S.; Felicioni, L.; del Grammastro, M.; Sciarrotta, M.G.; Buttitta, F.; Incarbone, M.; et al. Increased MET gene copy number negatively affects survival of surgically resected non-small-cell lung cancer patients. J. Clin. Oncol. 2009, 27, 1667-1674.

4. Okuda, K.; Sasaki, H.; Yukiue, H.; Yano, M.; Fujii, Y. Met gene copy number predicts the prognosis for completely resected non-small cell lung cancer. Cancer Sci. 2008, 99, 2280-2285.

5. Toiyama, Y.; Miki, C.; Inoue, Y.; Okugawa, Y.; Tanaka, K.; Kusunoki, M. Serum hepatocyte growth factor as a prognostic marker for stage II or III colorectal cancer patients. Int. J. Cancer 2009, 125, 1657-1662.

6. Corso, S.; Comoglio, P.M.; Giordano, S. Cancer therapy: Can the challenge be MET? Trends Mol. Med. 2005, 11, 284-292.

7. Birchmeier, C.; Birchmeier, W.; Gherardi, E.; Vande Woude, G.F. Met, metastasis, motility and more. Nat. Rev. Mol. Cell Biol. 2003, 4, 915-925.

8. Christensen, J.; Burrows, J.; Salgia, R. c-Met as a target for human cancer and characterization of inhibitors for therapeutic intervention. Cancer Lett. 2005, 225, 1-26.

9. Abidoye, O.; Murukurthy, N.; Salgia, R. Review of clinic trials: Agents targeting c-Met. Rev. Recent Clin. Trials 2007, 2, 143-147.

10. Eder, J.P.; Vande Woude, G.F.; Boerner, S.A.; LoRusso, P.M. Novel therapeutic inhibitors of the c-Met signaling pathway in cancer. Clin. Cancer Res. 2009, 15, 2207-2214.

11. Fujiwara, Y.; Senga, T.; Nishitoba, T.; Osawa, T.; Miwa, A.; Nakamura, K. Quinoline Derivative and Quinazoline Derivative Inhibiting Self-phosphorylation of Hepatocytus Proliferator Receptor, and Medicinal Composition Containing the Same. WO03000660 A1, 3 January 2003.

12. Mannoin, M.; Raeppel, S.; Claridge, S.; Zhou, N.; Savedra, O.; Isakovic, L.; Zhan, L.; Gaudette, F.; Raeppel, F.; Déziel, R.; et al. N-(4-(6,7-Disubstituted-quinolin-4-yloxy)-3-fluorophenyl)-2-oxo-3phenylimidazolidine-1-carboxamides: A novel series of dual c-Met/VEGFR2 receptor tyrosine kinase inhibitors. Bioorg. Med. Chem. Lett. 2009, 19, 6552-6556. 
13. Claridge, S.; Raeppel, F.; Granger, M.-C.; Bernstein, N.; Saavedra, O.; Zhan, L.; Llewellyn, D.; Wahhab, A.; Deziel, R.; Rahil, J.; et al. Discovery of a novel and potent series of thieno[3,2b]pyridine-based inhibitors of c-Met and VEGFR2 tyrosine kinases. Bioorg. Med. Chem. Lett. 2008, 18, 2793-2798.

14. Raeppel, S.; Claridge, S.; Saavedra, O.; Gaudette, F.; Zhan, L.; Mannion, M.; Zhou, N.; Raeppel, F.; Granger, M.-C.; Isakovic, L.; et al. N-(3-Fluoro-4-(2-arylthieno[3,2-b]pyridin-7yloxy)phenyl)-2-oxo-3-phenylimidazolidine-1-carboxamides: A novel series of dual c-Met/VEGFR2 receptor tyrosine kinase inhibitors. Bioorg. Med. Chem. Lett. 2009, 19, 1323-1328.

15. Raeppel, S.; Gaudette, F.; Mannion, M.; Claridge, S.; Saavedra, O.; Isakovic, L.; Déziel, R.; Beaulieu, N.; Beaulieu, C.; Dupont, I.; et al. Identification of a novel series of potent RON receptor tyrosine kinase inhibitors. Bioorg. Med. Chem. Lett. 2010, 20, 2745-2749.

16. Kim, K.S.; Zhang, L.; Schmidt, R.; Cai, Z.-W.; Wei, D.; Williams, D.K.; Lombardo, L.J.; Trainor, G.L.; Xie, D.; Zhang, Y.; et al. Discovery of pyrrolopyridine-pyridone based inhibitors of Met kinase: Synthesis, X-ray crystallographic analysis, and biological activities J. Med. Chem. 2008, 51, 5330-5341.

17. Schroeder, G.M.; An, Y.; Cai, Z.W.; Chen, X.T.; Clark, C.; Cornelius, L.A.; Dai, J.; Gullo-Brown, J.; Gupta, A.; Henley, B.; et al. Discovery of N-(4-(2-amino-3-chloropyridin-4yloxy)-3-fluorophenyl)-4-ethoxy-1-(4-fluorophenyl)-2-oxo-1,2-dihydropyridine-3-carboxamide (BMS-777607), a selective and orally efficacious inhibitor of the Met kinase superfamily. J. Med. Chem. 2009, 52, 1251-1254.

18. Zhao, A.; Gao, X.; Wang, Y.; Ai, J.; Wang, Y.; Chen, Y.; Geng, M.; Zhang, A. Discovery of novel c-Met kinase inhibitors bearing a thieno[2,3- $d]$ pyrimidine or furo[2,3- $d]$ pyrimidine scaffold. Bioorg. Med. Chem. 2011, 19, 3906-3918.

19. Matsumoto, S.; Miyamoto, N.; Hirayama, T.; Oki, H.; Okada, K.; Tawada, M.; Iwata, H.; Nakamura, K.; Ymasaki, S.; Miki, H.; et al. Structure-based design, synthesis, and evaluation of imidazo[1,2-b]pyridazine and imidazo[1,2-a]pyridine derivatives as novel dual c-Met and VEGFR2 kinase inhibitors. Bioorg. Med. Chem. 2013, 21, 7686-7698.

20. Schroeder, G.M.; Chen, X.-T.; Williams, D.K.; Nirschl, D.S.; Cai, Z.-W.; Wei, D.; Tokarski, J.S.; An, Y.; Sack, J.; Chen, Z.; et al. Identification of pyrrolo[2,1-f][1,2,4]triazine-based inhibitors of Met kinase. Bioorg. Med. Chem. Lett. 2008, 18, 1945-1951.

21. Gaudette, F.; Raeppel, S.; Nguyen, H.; Beaulieu, N.; Beaulieu, C.; Dupont, I.; Macleod, A.R.; Besterman, J.M.; Vaisburg, A. Identification of potent and selective VEGFR receptor tyrosine kinase inhibitors having new amide isostere headgroups. Bioorg. Med. Chem. Lett. 2010, 20, 848-852.

22. Qi, B.; Mi, B.; Zhai, X.; Xu, Z.; Zhang, X.; Tian, Z.; Gong, P. Discovery and optimization of novel 4-phenoxy-6,7-disubstituted quinolones possessing semicarbazones as c-Met kinase inhibitors. Bioorg. Med. Chem. 2013, 21, 5246-5260.

23. Williams, D.K.; Chen, X.-T.; Tarby, C.; Kaltenbach, R.; Cai, Z.-W.; Tokarski, J.S.; An, Y.; Sack, J.S.; Wautlet, B.; Gullo-Brown, J.; et al. Design, synthesis and structure-activity relationships of novel biarylamine-based Met kinase inhibitors. Bioorg. Med. Chem. Lett. 2010, 20, 2998-3002. 
24. Li, S.; Zhao, Y.; Wang, K.; Gao, Y.; Han, J.; Cui, B.; Gong, P. Discovery of novel 4-(2fluorophenoxy)quinoline derivatives bearing 4-oxo-1,4-dihydrocinnoline-3-carboxamide moiety as c-Met kinase inhibitors. Bioorg. Med. Chem. 2013, 21, 2843-2855.

25. Norman, M.H.; Liu, L.; Lee, M.; Xi, N.; Fellows, I.; D’Angelo, N.D.; Dominguez, C.; Rex, K.; Bellon, S.F.; Kim, T.-S.; et al. Structure-based design of novel class II c-Met inhibitors: 1. Identification of pyrazolone-based derivatives. J. Med. Chem. 2012, 55, 1858-1867.

26. D’Angelo, N.D.; Bellon, S.F.; Booker, S.K.; Cheng, Y.; Coxon, A.; Dominguez, C.; Fellows, I.; Hoffman, D.; Hungate, R.; Kaplan-Lefko, P.; et al. Design, synthesis, and biological evaluation of potent c-Met inhibitors. J. Med. Chem. 2008, 51, 5766-5779.

27. Friesner, R.A.; Murphy, R.B.; Repasky, M.P.; Frye, L.L.; Greenwood, J.R.; Halgren, T.A.; Sanschagrin, P.C.; Mainz, D.T. Extra precision glide: Docking and scoring incorporating a model of hydrophobic enclosure for protein-ligand complexes. J. Med. Chem. 2006, 49, 6177-6196.

Sample Availability: Samples of the compounds 15-20 are available from the authors.

(C) 2014 by the authors; licensee MDPI, Basel, Switzerland. This article is an open access article distributed under the terms and conditions of the Creative Commons Attribution license (http://creativecommons.org/licenses/by/3.0/). 